\title{
Wired by Weber
}

\section{The story of the first searcher and searches for gravitational waves}

\author{
Virginia Trimble $1,2, \mathrm{a}$ \\ 1 Department of Physics and Astronomy, University of California, Irvine CA, \\ 92697-4575, USA \\ 2 Queen Jadwiga Observatory, Rzepiennik, Poland
}

Received 28 October 2016 / Received in final form 5 November 2016 Published online 16 February 2017

(c) The Author(s) 2017. This article is published with open access at Springerlink.com

\begin{abstract}
Joseph Weber started thinking about possibilities for detecting gravitational waves or radiation in about 1955. He designed, built, and operated the first detectors, from 1965 until his death in 2000. This paper includes discussions of his life, earlier work on chemical kinetics and what is now called quantum electronics, his published papers, pioneering work on gravitational waves, and its aftermath, both scientific and personal.
\end{abstract}

\section{Introduction}

I was married to Joseph Weber for the last $28 \frac{1}{2}$ years of his life ${ }^{1}$, from 16 March 1972 until his death on 30 September 2000. My knowledge of his work during this period is largely firsthand. For earlier times, I have relied on published papers, narratives he wrote for various organizations, and the stories he told me. Items it occurred to me to check always turned out to be true, which is perhaps not entirely irrelevant to the rest of this story.

First we must decide what to call the phenomenon. "Gravity waves" sounds simplest and is sometimes heard, but the phrase was already in use for a process in the earth's atmosphere for which gravity is the restoring force. Exact parallel with the electromagnetic case would give us gravitational radiation, which has the advantage of definitely conveying the idea that energy is being carried, a point once in dispute. Standing waves exist, but no standing radiation! Weber used waves and radiation interchangeably over the years, but the current community has fastened

\footnotetext{
a e-mail: vtrimble@uci.edu; vtrimble@astro.umd.edu

1 This first sentence is a paraphrase of what Jennifer Homans (2012) wrote about her late husband, Tony Judt, in a very memorable piece in the New York Review of Books. I suppose it also counts as a conflict of interest statement. That the arrival date of the first LIGO event, 14 September 2015, was Joe's 15th Jahrzeit - anniversary of death, on the Jewish calendar - was called to my attention by his granddaughter, Elizabeth Weber Handwerker.
} 
onto "gravitational waves" at least partly because the word "radiation" tends to frighten or worry the uninitiated (like the word nuclear, most often when it is mispronounced as "noocooler", though I have never heard anybody say "radashiun"). I will use whichever words appear on original documents.

Curiously, the first generally-recognized pulse of gravitational waves (Abbott et al. 2016) reached Earth just 100 years (minus about 7 weeks) after Einstein submitted the first of his four famous November 1915 papers, "On the General Theory of Relativity" (Gutfreund and Renn 2015, pp. 161-162). All were submitted on Thursdays; perhaps this was just the day when the editor of the Sitzungsbericht of the Prussian Academy of Sciences opened his mail. "Cosmological Consequences in the General Theory of Relativity", which introduced the cosmological constant (Einstein 1917) was also a Thursday child (8 February 1917).

The normally-cited Einstein $(1916,1918)$ papers on gravitational waves arrived on 22 June and 31 January respectively, also Thursdays (Gutfreund and Renn 2015). In due course, he had second thoughts, of which more later, but I don't think he was ever quite so wishy-washy on the subject as indicated in The Economist's report of the LIGO event (Anon 2016).

\section{Background and early work}

Joseph (Yonah ben Yakov) Weber was born in Paterson, New Jersey on 17 May, 1919, the second son and last of four American-born children of Leah (Lena on some documents) Stein and Jacob Weber. The family name was originally Gerber and was changed to match a passport that was available quickly and cheaply when, in 1909, they decided to leave the part of the Russian Empire now called Lithuania. Joe's first name arose from a misunderstanding when his mother went to enroll him in school, and his near-lack of the standard regional/ethnic accent was due to his being knocked down by a bus at age five and having to be re-taught to speak by a therapist from Philadelphia (at public school expense, incidentally).

By age 10, Weber had assembled his first crystal set and joined the Passaic County Amateur Radio Club. Not long after, he contributed to the family excheqeur by working in a radio store, which he found both more interesting and more remunerative than a paper route or caddying. He graduated from the Paterson Talmud Torah and Eastside High School already in love with a class mate, Anita Straus, who went on to Smith College, receiving a BA in physics in 1940. Joe's high school annual describes his activities as Mathematics Club and Orchestra; his hobbies as Amateur radio, chemistry, and astronomy; and characterizes Ambition as "????". Classmates had mentioned money, travel, reading, and cooking as "ambitions" in the year book.

Joe looks younger than most of his classmates, as indeed he was. Thus, although he had received a congressional appointment to the US Navy Academy (USNA) in 1935, he was initially too young to be admitted, and spent a year at Cooper Union, though a good deal of his education also came from the Danforth Memorial Library in Paterson. He described his favorite book as Maxwell's Relative and Absolute Motion, which apparently does not exist. The editors suggest that the book might actually have been the 1876 Matter and Motion.

Weber graduated from the USNA with the class of 1940. Among his accomplishments as an Annapolis cadet was wiring the mess hall for sound, so that one fine evening the tones of Schubert's Great C Major symphony drowned out the clatter of cutlery and the chatter of cadets. His first assignment was to the aircraft carrier Lexington, and he was above decks when she was sunk in the battle of the Coral Sea on 8 May 1942 (having steamed out of Pearl Harbor on 5 December 1941). Part of his compensation for "articles lost in a marine disaster" purchased an engagement ring 
for Anita, and they married not long after Navy rules permitted this. She continued teaching high school physics for several more years.

His next task was skippering the submarine chaser SC 690, which had six inch guns and a $10 \mathrm{~cm}$ radar, neither standard equipment, but the result of his scrounging and ability to maintain things. After participating in the first wave of the Sicilian landing, he spent a year studying electronics at the Naval Postgraduate School and was then assigned to run electronic countermeasures for the Bureau of Ships.

When Weber resigned his Navy commission (as lieutenant-commander), he was offered jobs by several of the companies that had received grants from his office, but instead he accepted a full professorship of electrical engineering at the University of Maryland in 1948. They requested (firmly!) that he earn a Ph.D. in something, somewhere, soon. Peebles et al. (2009) describe his interaction with George Gamow at George Washington University, which might be described as one of at least half a dozen near misses at pre-1965 discovery of the cosmic microwave background radiation. In the event, Joe became a graduate student at the Catholic University of America while both a Maryland professor and a consultant at the Naval Ordnance Laboratory, as was his thesis advisor, Keith Laidler (1916-2003), a native of Liverpool, who returned to Canada not long after Weber's 1951 Ph.D. (not, as far as I know, causal).

\subsection{Chemical kinetics and the inversion spectrum of ammonia}

Ordinary ammonia, $\mathrm{NH}_{3}$, has a strong microwave (K-band) absorption feature at $1.25 \mathrm{~cm}(24 \mathrm{GHz})$, a splitting that results because the $\mathrm{N}$ can be on either side of the triangle of $\mathrm{H}$ atoms. Deuterated ammonia $\left(\mathrm{NH}_{2} \mathrm{D}\right)$ has a similar feature, but at a different frequency. Weber's thesis experiment used a ten-foot microwave waveguide filled initially with $\mathrm{NH}_{3}$ and a supply of $\mathrm{HD}$ deposited on the walls. The changing strength of the two absorption features when broad-band microwaves propagated down the waveguide revealed the rate and amount of the conversion of $\mathrm{NH}_{3}$ to $\mathrm{NH}_{2} \mathrm{D}$ (Weber and Laidler 1950, 1951a,b; Weber 1951). In the course of the experiment, they measured the wavelengths of the transitions more accurately than anyone before or for sometime after.

Related work included Kurt Shuler and Weber (1954) on ionization in flames, and the construction and use of a Stark effect microwave spectrometer (Marshall and Weber 1957a,b) applied to OCS, previously studied by the Townes group. This was Sam Marshall's Ph.D. thesis, with Weber as the effective advisor, though their affiliations were listed as Naval Ordnance Lab and CUA (Marshall) and NOL and U Md (Weber). Weber and Laidler both listed NOL and CUA. I have not seen a copy of Weber's actual thesis and am not sure that he even had one by 1972. Joe had several other students during his days in the electrical engineering department, but his name did not appear on their papers, they are not listed on his CV (nor are his physics students), but some remained close friends.

\subsection{Inverted populations as amplifiers}

Graduate physics at Catholic University around 1950 was largely taught in weekly 7-10 PM classes (good for returning veterans with day jobs), and largely taught by Karl Herzfeld, who had served for Austria in WWI, coming to the United States in time to escape the horrors of being Jewish there before and during World War II and also in time to be John A. Wheeler's thesis advisor. Joe recalled that, the moment he heard about the Einstein A and B coefficients, he realized that a population of molecules with more of them in an upper than in a lower energy state could be used as an amplifier. 
So, in March, 1951, Weber went into the lab, constructed what we would now call an ammonia molecular beam maser, and learned that it worked as a very high resolution spectrometer, but that a solid state device would be needed to make an amplifier with a useful gain-band-width product (Weber 1959a,b). Bloembergen (1956) had made the same point. According to the review (Weber 1959b), the first observation of weak maser-type amplification was in 1950 by Purcell and Pound (1951), who looked at resonance of the $\mathrm{Li}^{7}$ nucleus in a $\mathrm{LiF}$ crystal when it was moved very quickly from a strong magnetic field to a field pointing the opposite direction, resulting in an inverted level population and so a negative temperature in a Boltzmann equation.

During 1951-52, Weber discussed amplification by ammonia at seminars at Princeton and in the Washington area and at a 1952 IRE meeting in Ottawa Canada, under the title "Amplification of microwave radiation by substance not in thermal equilibrium" (Weber 1953a). Later that same year, there came a letter dated 23 November 1953 from Charles H. Townes, requesting a reprint of the paper, because, he wrote, he had a student named J.P. Gordon, who was working "on a related topic". The authors of the eventual Columbia paper (Gordon et al. 1954) were J.P. Gordon (called Jim), a graduate student who never finished his Ph.D. and H.J. Zeiger (called Herb), a postdoc who had completed a Ph.D. under I.I. Rabi (Johnson 2016). And then there were Basov and Prokhorov.

This requires a bit of expansion. That meeting was the Electron Tubes Conference of the Institute of Radio Engineers, and the publication was in the Proceedings of the Institute of Radio Engineers, Professional Group on Electron Physics. Weber had joined the IRE in 1944, became a full member in 1946, a senior member in 1953, a fellow in 1958, and a life fellow in 1985, for which the requirement was that the sum of a member's age and his years of fellowship exceed 100, and no, the arithmetic doesn't quite work out. In any case, in the interim, the IRE had merged with the Institute of Electrical Engineers (IEE) to become the IEEE, the Institute of Electrical and Electronic Engineers. A recently deceased German-Israeli-American engineer whose memberships followed a similar course once assured me that the IRE was the more prestigious of the merging Institutes.

Secondary sources (Campbell 1960; Kastler 1985; Thorne 1994; Glanz 2000) sometimes mention Weber's talk and paper as the first "open" description of what became masers and later lasers (the word was a Townes coinage). The explanation is a May, 1952 presentation by Basov and Prokhorov who "pointed out the theoretical possibility of a device producing microwaves by using stimulated emission at an All-Union conference on radiospectroscopy". (Kastler 1985, who should not be blamed for the misspaced prepositional phrase because he was quoting from a textbook by Bertolotti 1983). The Soviet paper appeared after the Gordon et al. (1954) one (Basov and Prokhorov 1954).

Some other items worth noting: first, Townes's first, actual, physical maser used ammonia gas. Second, Donald H. Menzel (1937) had earlier remarked that radiation passing through interstellar gas could, in principle, be amplified rather than absorbed, though he expected the effect to be small; several interstellar molecules, including $\mathrm{CH}_{4}$ and $\mathrm{H}_{2} \mathrm{O}$, do in fact mase. Third, when Weber was elected to the University of Maryland Engineering Hall of Fame in 1988 the citation was for the earliest publication of quantum electronics principles. Fourth, when he first visited UC Irvine in February 1972, most of the then-members of the department (from Fred Reines and John Pelham on down in age) already knew or knew of him for that work and were the first to inform me that he should have shared the Nobel Prize.

Weber taught microwave engineering and related subjects at the University of Maryland from 1948 until about 1961, when he gradually moved from the engineering department into physics and began to teach quantum mechanics and all the other ills to which the physics flesh is heir. A baker's dozen papers (Weber 1953a, 1954a,b,c, 
1955, 1956a,b, 1957, 1960b,c,d, 1961b; Weber and Hinds 1962) deal with a wide range of topics concerning various forms of electromagnetic radiation, many theoretical, and few with "maser" in the title or abstract. In 1959, when he was asked to review the topic for Reviews of Modern Physics (Weber 1959b), only four of the many references were to his own work - the primordial IRE paper, one each on vacuum fluctuation noise and maser noise considerations, and the Gravity Research Foundation prize essay that already looked forward to the use of maser amplifiers in possible designs for gravitational wave detectors (Weber 1959a).

The review also has a discussion of the energy levels of ruby and its properties as a potential amplifier. The second ring Joe ever gave me was a glorious emeraldcut laboratory grown ruby (set in yellow gold, with diamonds on either side, and accompanied by a biblical passage generally quoted as "a woman of valor", with a mention that his life would have played out very differently if he had known about rubies in 1952, but that he had no regrets). The first ring? That was the Tiffany solitaire engagement ring and wedding band, a few weeks after we met.

Some additional background material, from my point of view, appears in Trimble (2000, 2014, and 2016). As late as 1969, Weber was asked by Gordon \& Breach Publishers to edit a pair of volumes of reprints of critical papers from the history of masers (Vol. I) and lasers (Vol. II) with commentary.

The actual affiliation listed on Weber (1953a) and other early papers is the Glenn L. Martin College of Engineering and Aeronautical Sciences, University of Maryland, College Park, Maryland. Apparently the then university president, "Curly" Bird had tried to recruit von Kármán to head up the new school and got the response, "Mr. Bird, where is Maryland?" From 1954-55 onward, progress in understanding and constructing masers and their ilk, as spectrometers, frequency standards, and amplifiers, proceeded quite rapidly among a fairly compact set of institutions including Columbia, Bell Telephone Labs, Princeton, and MIT. The best guide to who did what, when, and how is probably the articles reprinted and the commentary given by Weber (1969a,b), unless you prefer a whole book like Bertolotti (1983). One microfactoid: while Purcell and Pound's (1951) experiment used magnetic fields to invert a thermal population, Weber's first operating device, a spectrometer in effect, used a reversing electric field.

A couple of more sidelights: (1) Good (1946) is a wonderful introduction to the inversion spectrum of ammonia, well written even by the higher standards of the time. (2) A reasonable question is "why did he publish there?" The answer is on page 51 of the reprint volume Masers (Weber 1969a).

"As noted earlier, I had presented a discussion of this principle at the 1952 Ottawa electron tube research conference. It had been my intention to publish these results in a widely read journal. Early in 1953 Professor H.J. Reich of Yale University wrote to say that he had been chairman of the 1952 electron tube conference program committee, and was also editor of a (not so widely read) journal. As a result the conference summary report was published in the June 1953 Transactions of the Institute of Radio Engineers Professional Group on Electron Devices". Near the end of his career, when most physicists had no use for results from room-temperature bar detectors for gravitational waves, Weber again published largely in low-prestige journals and conference proceedings.

But, when Weber became entitled to his first sabbatical, for 1955-56, he chose to go to Princeton with a pair of fellowships, on which J. Robert Oppenheimer and John A. Wheeler would be his advisors. In other words, he had started to think about gravitation, and he actually spent the second half of that academic year in Leiden with Wheeler, where the widow of Paul Ehrenfest (Tatiana Afanassieva, who published at least one paper with her husband) gave him the photograph of Einstein that appears as the frontispiece of his textbook (Weber 1961a). 
Joe's love of tinkering survived the grim years of "Weber never did anything right" in the physics community, and our dining room featured a traditional oil-burning Shabbas lamp fitted with flickering tiny lightbulbs. He always picked the simplest solution to a mechanical problem that would work: a piece of string to lengthen a pull chain on a lamp, duct tape when I sawed through the long cord on the electric saw trying to get ivy off the house (some of which, unfortunately, was poison ivy), tightening the screws on the rattling dash board of our 1968 Camaro. And Weber picking the correct capacitor or resistor from a box of miscellaneous components was a joy to watch.

Collins (2004) recorded that he had been driven by Weber from the University to the gravity building in what he described as an old car. It was not the 1968 Camaro, which was one of our California cars. In fact, since the year was 1975, it was either Tweedledee or Tweedledum, the near-twin 1964 and 1965 Dodges that served perfectly well until a tree falling from the grounds of the Chevy Chase Country Club destroyed the garage and Tweedledee inside. The house, which Collins wrote that he had not seen, had five bedrooms, typical for Chevy Chase, and when the sad moment came that I had to sell it after Joe died, it went on the market as what a colleague called "a million dollar fixer-upper???" because neither of us was very good about taking time away from science to worry about interior paint and carpets, or new appliances, when the old ones worked just fine. Some of the money endowed the Joseph Weber Award in astronomical instrumentation for the American Astronomical Society.

\section{The paper trail}

No complete list of Weber's publications exists. This is not uncommon; I found the same thing while writing an entry for the Biographical Encylopedia of Astronomers (Hockey et al. 2014) on Thomas Gold ${ }^{2}$. What happens is that the author gives a talk at the Tierra del Fuego conference or submits a paper to the journal Cosmologica Acta et Retracta and enters the preprint into his ${ }^{3} \mathrm{CV}$, but, when the proceedings finally appear or the paper is accepted and published a year or two later, he never goes back to fill in the details.

This phenomenon is particularly true here because so many of Weber's later papers were in conference proceedings, especially after the American community had decided to disbelieve his work. Colleagues in China, India, France, Italy, Pakistan, and a few other places (there was Malaysian currency in a drawer with all the rest when he died) continued to invite him to give talks at their meetings. But, as a lower limit, he was the author or co-author of at least 130 papers, dated 1950 to 2001, with at least 35 co-authors, never in large groups. He presented research results at a minimum of 50-some conferences, not counting meetings of the American Physical Society, from 1950 to about 1998.

The early papers were in chemical kinetics, as mentioned in Section 2.1. Then came "Amplification of Microwave Radiation by Substance not in Thermal Equilibrium",

${ }^{2}$ Gold, by the way, taught general relativity at the Cavendish Lab in Cambridge UK in 1949-53, so the subject was not completely neglected even in this period of relative disinterest. Peebles (2016) elegantly presents the American recovery of experimental gravity physics elsewhere in this volume. Blum et al. (2015) have recently discussed this "low water mark of GR" and its "Renaissance" in the context of an international historiographical framework and with references to a number of other authors and papers who earlier perceived a similar structure to the history. I am reluctant to copy out their references, lest it give the impression that I have read them.

${ }^{3}$ Well, yes, women (including me) also make this mistake, and I occasionally have to ask an editor or organizer, "What ever became of. ..?" Don't you? 
from that 1952 talk (Weber 1953a). The missing article was characteristic; Weber's speech was always slightly laconic and hesitant, a lingering relic of the speechless year, and he said that social conversation should not be a competitive sport. Quantum electronics publications ended with the edited volumes on masers and lasers (Weber 1969a,b).

Meanwhile, publications on gravitational waves began with Weber and Wheeler (1957), which addressed their reality (next section) and continued to the end (Weber 2000). This last paper is a bit of an embarrassment. I have a copy; I know it was accepted because the proofs came shortly after Joe died; I corrected the proofs (about which he had been very concerned in his last days) and returned them along with a couple of paragraphs of biographical material requested by the editor. But I cannot remember the name of the journal (or the editor) concerned, and it was a sufficiently non-prestigious one that the paper is not to be found by the Astrophysics Data Service.

The textbook (Weber 1961a) General Relativity and Gravitational Waves was, he later said, part of his effort to learn the subject thoroughly. I read it in about 1963, long before I met the author, because it was the thinnest GR text on the library shelves at UCLA when I thought I should learn something about the field, which was not then taught there. His attention to possible coherent detectors for neutrinos began with Weber (1981a) on "Exchange of Energy with Large Numbers of Particles" and also continued to the end.

I have copies of very few of these papers, though the archives at the University of Maryland Library took, and I assume still has, one of each item that was in his files in fall, 2000, including proposals, referees' reports both written and received, letters to and some copies of letters from Joe, and so forth. Most of the conference volumes from his Maryland office, the Chevy Chase house, his UCI office, and our Irvine apartment were donated to the Niels Bohr Library of the American Center of Physics in Maryland, along with hundreds of others of his books, and a good many of mine from Maryland home and office. The library disposed of conference proceedings only when they were duplicates, and most were not.

The sole-author papers in the reference list from 1951 to 2001 are intended to provide a summary of Weber's work as presented in the (relatively) more accessible publications. Not all are explicitly cited in the present text.

\section{Does gravitational radiation exist? What others thought}

Wave-like solutions to the equations of general relativity were never in doubt. The critical point is whether they would carry energy away from accelerated mass quadrupoles. This is more difficult. Indeed even in the electromagnetic case, there are both advanced and retarded potentials, and it is in some sense left for observations to decide that we see only the latter. There was, once upon a time, the Wheeler-Feynman (1948) absorber theory of radiation, supposed to provide an explanation, if the universe were either closed or in steady state. Curiously, that was what Feynman chose to talk about in a seminar organized by Caltech students soon after the October 1965 announcement of his Nobel Prize (I was there, part of a little coven of astronomy grad students somewhere near the middle of the auditorium).

Even before general relativity, Poincaré (1905) was an early ("first" is always dangerous) proponent of the idea that gravitational information must travel in wave form to convey to the surroundings of some system that the system has changed and that masses in the surroundings must respond accordingly. Poincaré is also supposed to have been the person Einstein said would have been most likely to discover a general theory of relativity if he himself had not (this is strictly third-hand rumor). Poincaré's view was predicated at least partly on analogies with electromagnetic radiation, also 
made use of by Feynman (1962-63-63), Weber (1961b), and many others. Levi-Civita (1917) denied the physical reality of gravitational waves because the covariant stressmomentum-energy tensor is equal to zero. It is conceivably not a coincidence that he was the president of the Commission on Relativity of the International Astronomical Union when it voted itself out of existence in 1925.

Different discussions of gravitational waves give rather different sets of physicists credit and blame for doubting existence and establishing it, Weber's own (1961a) version counted on the side of the angels Einstein (1916, 1918), Eddington (1923), Fierz and Pauli (1939, on what sort of wave would go with a spin-two graviton), Landau and Lifshitz (1951, there are many other editions in multiple languages), Bonnor (1954), Lichnerowicz (1955), Foures-Bruhat (1956), Bondi (1957), Pirani (1957), Brill (1959), Robinson and Trautman (1960) and naturally Weber and Wheeler (1957). You will not find "Bonnor (1954)" in the references here. I think it must be a ghost of Bonnor (1959) on "Spherical Gravitational Waves", in which he calculates, using retarded potentials, that the loss of gravitational mass from a system is equal to the energy carried by the waves, when you go beyond the linear approximation, and for the case that the changing quadrupole moment is driven by a non-gravitational force, for instance a spring connecting two masses. He states that he has been unable to "find an answer for the case of an isolated system with only gravitational forces".

The waves are of Petrov (1954, cited by Petrov 1962) type II. Feynman (1962-63), like Fierz and Pauli (1939) was primarily interested in a particle approach, showing that you would get GR as what was carried by a spin-two, massless particle. He writes "graviton" as if it were an old word, which it was, having (according to the Oxford English Dictionary) appeared as far back as 1942 in Chemical Abstracts, which spoke of "plane waves of a particle of spin 2 (graviton)".

Of standard texts, Møller (1952) has no interest in the topic; Adler et al. (1975) regard the linear, weak-field case as suitable for an introductory treatment; Hartle (2003) gives us two chapters, going from the weak, linear case up to strong field calculations. And the one you've all be waiting for (because you weren't strong enough to carry it with you), Misner, Thorne, and Wheeler (1973) ask the student to follow Bondi $(1957,1965)$ and Bondi and McCrea (1960) in showing that you can extract energy from a gravitational wave and use it to heat a stick, a real effect though a gedanken experiment. They provide the standard quadrupole formula for energy radiated by point masses in a binary system (tiresomely in $c=G=1$ units), which made an early appearance in a book on interstellar communication (Dyson 1963). The exercise for the student is 18.5 , and, in due course, they devote chapters 35,36 , and 37 to a mathematically intense treatment of gravitational waves.

Peebles (2016, elsewhere in this volume) says that the issue of existence was never in doubt after 1957, relying on the argument given by Weber and Wheeler (1957).

How could existence ever have been questioned, and who dared oppose this team of heavyweights? Well, it all started with Einstein and Rosen (1937). The story has been well told by Kennefick (2007), though I first heard it from Martin Blume, former editor in chief for the American Physical Society. He had looked back in the files of the Physical Review, to which that paper was first submitted, and refereed (anonymously) by H.P. Robertson, who gave the same advice directly to Einstein. Results were the published paper, with many changes, and Einstein's resolve never again to send anything to Physical Review. Items that it was possible to get wrong included whether the part of the stress-energy tensor representing a traveling wave could be transformed away by repeated jiggling of reference frames and whether a particle hit by a wave would be moved and so absorb energy. The answer to that is no, if you forget to include the radiation reaction as it re-emits. Similar things can be said about electromagnetic radiation. Another way of describing the problem is to say that the equation of motion of a particle is not damped by the radiation term (Infeld 1938). 
Indeed, my impression is that Leopold Infeld was the key player on the opposing team. The standard place to start is Einstein et al. (1938), which dealt with the problem of motion in Einsteinian gravity (not yet fully solved, in the view of Damour 1987) and which is said to have distressed Banesh Hoffmann by the non-alphabetically ordering of the authors. At any rate, Infeld produced a steady stream of anti-gravitational radiation papers (Infeld 1936, 1937, 1938, 1954, 1956, 1957, 1959), in due course involving his students (Infeld and Wallace 1940, Infeld and Schild 1949) and others (Infeld and Plebanski 1960, Infeld and Scheidegger 1951, Infeld and MichalskaTrautman 1960). He appears to have handed over to Scheidegger (1953 and elsewhere), whose review of existence vs. non-existence also mentions points about energy content of the waves being zero and the transforming away of the wave part of the stress-energy tensor. Even Eddington (1924) worried a bit about the choice of coordinate systems, since it seemed to him that the velocity of propagation of gravitational information would be equal to the speed of light only for a properly chosen set of coordinates. At various moments, Weyl (1944) and Rosen (1956) were also non-believers.

Let's stop for a moment with Bonnor's (1959) calculations, using retarded potentials. He states clearly that, in second-order approximation, the mass lost by a system with an oscillating quadrupole moment is exactly equal to the energy carried by waves calculated in the first order approximation... for a system driven by non-gravitational forces, like a pair of masses joined by a spring, set into oscillation. But he is unable to reach the same conclusion if the system is isolated and only gravitational forces are at work.

By the time of the 1959 Royaumont conference, essentially all the participants agreed that gravitational waves could carry energy, if properly calculated and not considered in infinite space(-time), for which energy is not well defined. This is not the same as saying energy is zero! In the concluding remarks, however, Bergmann (1962) said that it had probably been unfair of them to reach this conclusion in the absence of the strongest opponent. He expressed hopes that Infeld would be at the next such meeting in a few years. Four other Polish physicists appear on the list of participants and Fock, Ivanenko and Petrov from the USSR.

Bergmann also expressed hopes for major contributions to cosmology from radio astronomy and for improved neutrino detection devices that could reach sources beyond earth. His precise words near the end were "If one of Weber's schemes to observe gravitational radiation should become realistic, that, too, would provide us with a completely new channel of information". Bergmann's English was largely British, so "scheme" did not sound quite so pejorative to him as it does to Americans now. His French text speaks of "dispositifs imagines" as the equivalent of schemes. In any case, by the 1962 GR3, his view was that there was no point in Weber's work and that nothing would come of it for 100 years. The remark may well appear in some report of the meeting, but I remember it as a Weber quote. Peter was anyhow approximately half right on the time scale!

Surely by now opposition has died out (in the sense claimed by Planck)? Not entirely. An arXiv posting by Loinger (2003) is described as a history of the discovery of the non-existence of gravitational waves. Rather impressively, only two days after the public announcement of the LIGO burst, Loinger and Marsico (2016) had produced a single page called "On LIGO's Detection of a Gravitational Wave", concluding that no gravitational wave can be emitted, because the gravitational trajectories of the interacting bodies of an ensemble (with no other forces) are geodesic lines (compare Bonnor's conclusion above). A large number of Italian institutions are represented on the LIGO team (Abbott et al. 2016) but apparently not the University of Milan, Loinger's home institution.

Perhaps nothing to do with the story, but Infeld's disciple Scheidegger spent most of his career at Imperial Oil Ltd, Calgary, and Infeld himself seems to have had 
particularly bad luck, even by the norm for Jews from Poland born in 1898. Canada had no Joseph McCarthy, but they did send him back to Poland as a suspected Communist after he had spent more than a decade there. Historian and philosopher of physics Allen Janis (personal communication, May 2016), who knew most of the people involved in this issue, tells me that Infeld's Canadian-born second wife never learned to speak Polish, making their 18 years back in Warsaw less pleasant than might otherwise have been the case.

\section{The pioneer}

The version of the story Joe told me began with one of his young sons banging his head against the wall at night, keeping his father awake and with extra time to start thinking about how he might bring what he called the beautiful theory of general relativity into contact with laboratory experiments. At any rate, he took his fellowships from the Guggenheim Foundation and the National Research Council in 1955-56 up to Princeton (the University and the Institute for Advanced Study) with J.R. Oppenheimer and J.A. Wheeler to be his advisors. Weber had some amusing Oppenheimer stories, but it was with Wheeler that he headed to the Lorentz Institute for Theoretical Physics in spring, 1956. Anita, who had to cope with the shopping and child-care, learned some Dutch; Joe did not. Lest we not pass this way again, he later held another Guggenheim (1962-63) again at Princeton and a Fulbright (summer 1963). A Wheeler/Princeton custom which followed him the rest of his life was the bound lab notebook, with numbered pages, into which went notes from colloquia and meetings, calculations of anything he thought should be calculated, equipment designs, and updates on the status of experiments, for instance the equivalent noise temperatures of the bar detectors each time he rang them down from input electrical signals. He is writing in one of those notebooks in the "Gravity Building" in one of the photos on file at the Emilio Segrè Visual Archives at the American Center for History of Physics in College Park. Another of those photographs shows, higher in the room, the lovely Japanese figure of a woman in white, the only mistress, Joe said, his first wife would allow him.

Weber had been working on various aspects of electromagnetic radiation, so he naturally thought of ways that energy from gravitational waves might drive changes in the Maxwell tensor (Weber 1980). The first designs that made it into print (Weber 1959a, 1961a, 1962a) show a pair of masses connected by a spring (energy to be extracted from the wire) and then two very massive piezoelectric crystals, connected to amplifiers and a receiver to cross-correlate the outcoming electric currents and look for relative motion between the crystals. A minor aspect of "national culture" is that Weber nearly always represented his detectors with equivalent circuits, with a driving voltage, resistance, inductance, and capacitances (Figs. 1 and 2), while Bondi (1957, 1962) and others trained in Britain tended to think of "springs and dashpots".

The next attempt, with Robert L. Forward and David M. Zipoy, was to design a high frequency pumped parametric capacitor, coupled to the end of a massive cylinder. Later, Hirakawa at the University of Tokyo explored the capacitor strategy (Hirakawa and Narihara 1975), as did Jean-Paul Richard (1976), who had joined the University of Maryland physics department after Weber moved over from engineering ${ }^{4}$.

Weber also looked briefly at the possibility of a free-mass interferometer (Forward 1971, 1978; Moss et al. 1971). I enter the story peripherally at this point, because

\footnotetext{
${ }^{4}$ Hirakawa remained on the list of people with whom we exchanged holiday cards at year's end for several years, and I believe he died fairly young of tuberculosis. Richard's decision to go his own way obviously did the Maryland gravitational wave group no good in community eyes.
} 


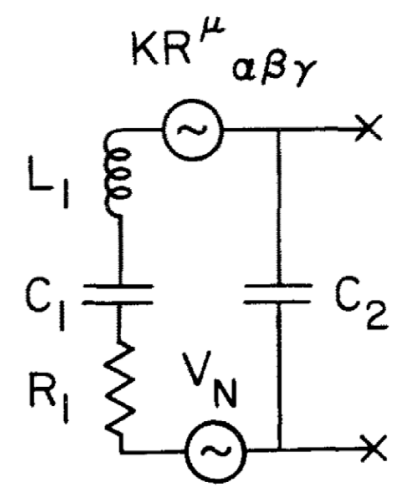

Fig. 1. Equivalent circuit for a bar antenna. $\mathrm{KR}_{\alpha \beta \gamma}^{\mu}$ is the Riemann tensor that stretches and compresses the bar, creating electric currents in the crystals. $\mathrm{V}_{N}$ is all the noise sources put together. From Weber (1984), on p. 1186.

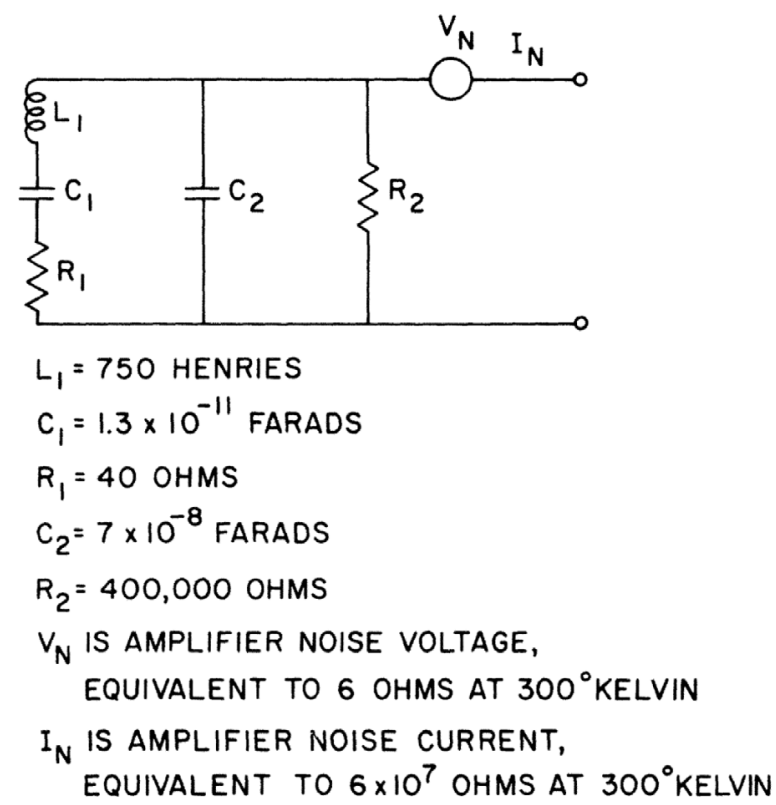

Fig. 2. Equivalent circuit for the "noise" part of the bar detector in the Gravity Building in June 1974, with numerical values of the inductances, capacitances, resistors, and voltages. From Lee et al. (1976), on p. 897.

I knew Bob Forward slightly from his occasional attendance at general relativity seminars at Caltech in 1966-68, when I was a graduate student there. He invited me back home to southern California from a postdoc in Cambridge, England, to spend a couple of weeks in December 1969 at Hughes Research Lab (where he had returned after completing his Ph.D. and a short postdoctoral term with Weber in Maryland). Forward said his goal was to teach me to be a systems engineer, but what I actually calculated for him were (a) the amount of gravitational radiation to be expected from a pulsar if its quadrupole moment was what was implied by glitches being starquakes in which mountains smoothed down and (b) what astronomical sources could be reached optically with some new form of intensity interferometry. The answers were 


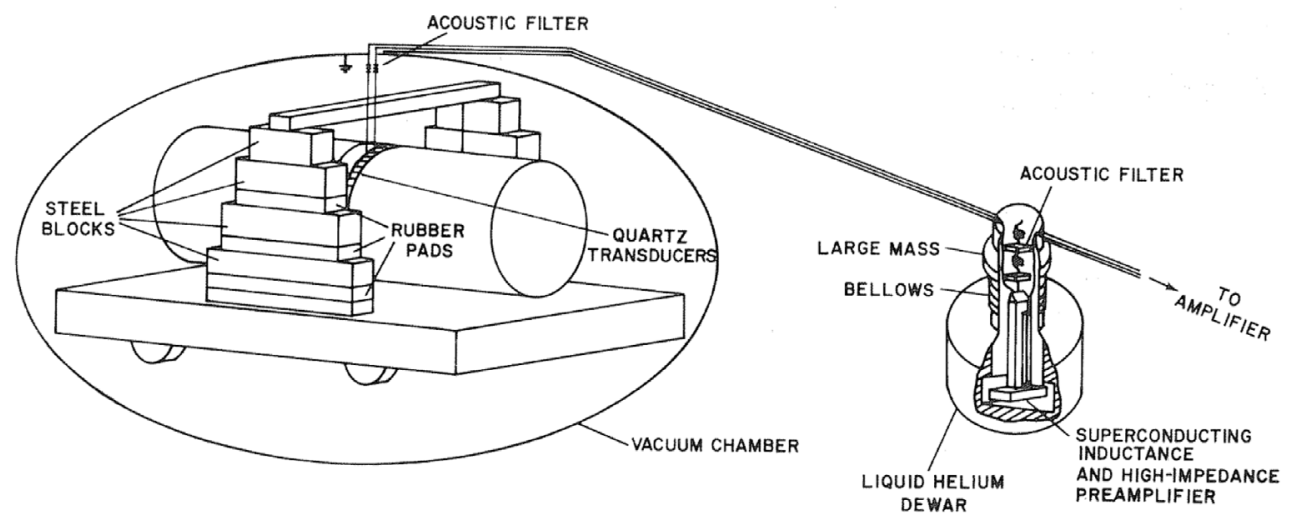

Fig. 3. The bar detector design as of 1964. Filtering, preamplifiers, mid amplifiers all became more complex over the years, and the quartz transducers were replaced by PZT. From Weber (1980), on p. 453.

(a) not much and (b) the sun. But while there I saw his first (Forward 1971) free-mass interferometer intended as a 3-meter long detector for gravity waves. The substrate was a granite slab from a supplier of gravestones. Forward later operated a somewhat larger free-mass interferometer that reached a sensitivity in displacement of the masses of about one part in $10^{15}$ (Forward 1978). Rainer Weiss (1972) at MIT had begun thinking along the same lines after completing a balloon experiment to study the microwave background radiation.

Forward at the time spoke very highly of Weber, and he was one of Joe's two best men when we married a second time in a synagogue in Orange County.

Meanwhile, back at the College Park ranch, Joe had realized that enormous piezoelectric crystals probably didn't exist (advertizing literature from the period talks about sizes measured in centimeters not meters) and that they weren't necessary. Instead, one could take a many-kg mass of something cheaper and stiffer, use it as the detector and take the energy out via hand-size quartz or PZT (lead-zirconate-titanate) crystals attached firmly to the bar. One of the group members later remarked that chunks of tungsten went glump when you hit them, but aluminum rang. The first published plans (Weber 1959a,b, 1961b) show single massive crystals, but the first thing actually built was a modest, $8^{\prime \prime}$ diameter aluminum bar with quartz crystals bonded to it (Fig. 3).

Other bar detectors were built through the 1960's, with graduate student Joel Sinsky (interviewed and celebrated by Collins 2004) traveling to superintend the construction of both the aluminum bars and the crystals, the latter coming from Gulton Industries and Clevite. A good deal of experimenting was also needed to identify the right adhesive to attach crystals to bar, and the most-reproduced photograph from this period shows Weber bending over a bar, gluing on crystals or attaching wires to them to bring the signal out of the giant vacuum chambers that held the bar and disk detectors (Fig. 4). I remember Eastman 910 (pronounced nine-ten) and Araldite cement.

Aluminum bars of various sizes and shapes, at various temperatures have Q-values (ring-down time in units of the resonant periods) up to 100000 to 500000 (Weber 1980). They must be isolated acoustically and electromagnetically from everything you can think of that is not a gravity wave, and all of the longer Weber papers have discussions of some aspects of the problems. At best, they will have noise temperatures near room temperature, unless you go to cryogenic systems, and no one expected 


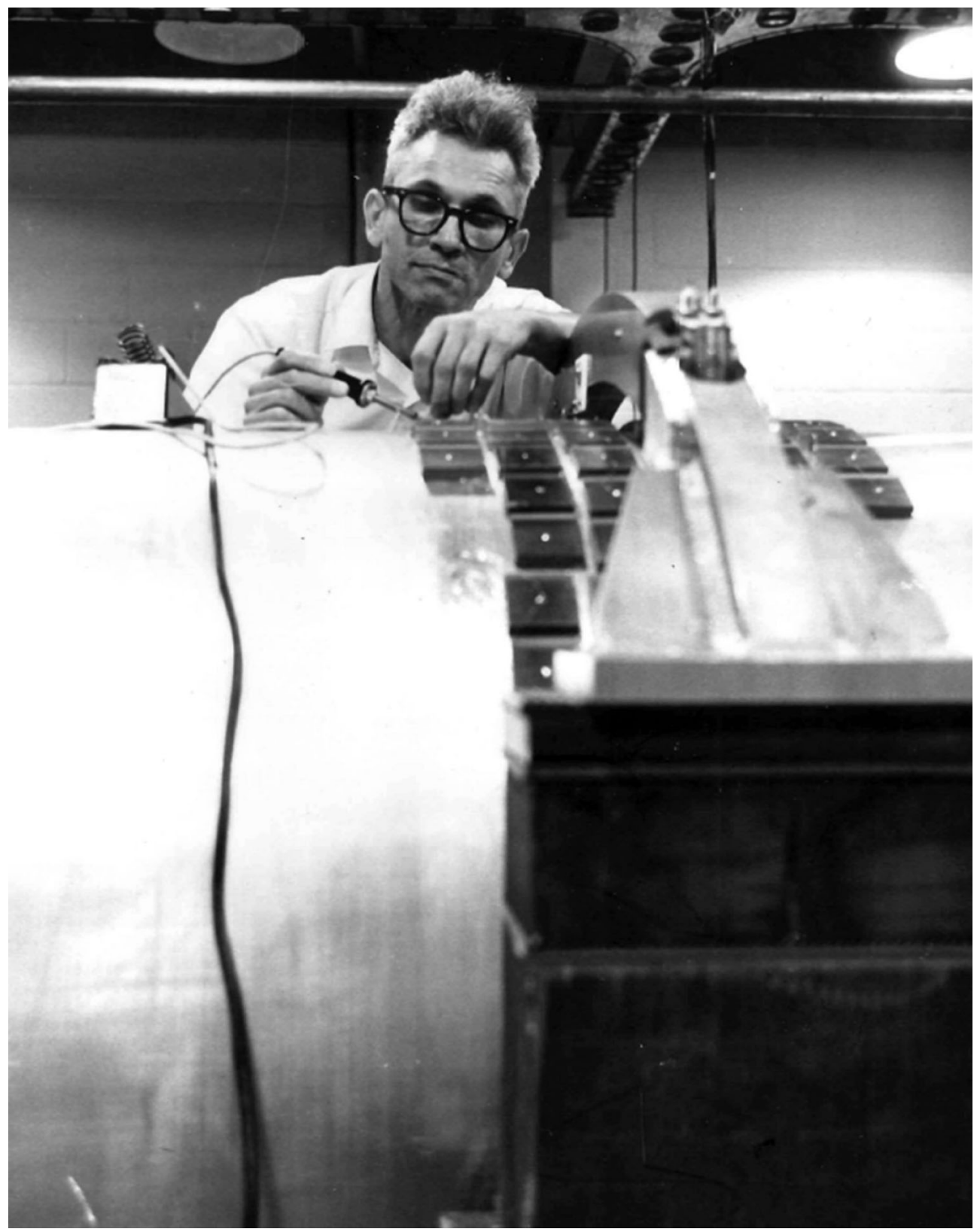

Fig. 4. One of the several standard images of Weber posed as if working on a bar antenna, either gluing on crystals or soldering them to wires that would connect to the outside. Probably 1969.

signals anything like that powerful. Thus the goal was to operate two or more antennas further apart than the reach of earth tremors, power failures, cosmic ray showers, noisy traffic, and so forth.

One could then look for instants of coincident high output from two or more bars. First these were at different places on the University of Maryland campus, then, with increased funding, in a specially-built "Gravity Building" near the university golf 
course, and, for the data runs that led to the first announcements of evidence for the detection of gravitational radiation (Weber 1968c, 1969c), there was a large bar each in the Gravity Building and at Argonne National Laboratory near Chicago, where Roy Ringo kept an eye on things between Weber's frequent visits.

Initially, the electrical signal was transmitted back to College Park from Argonne via dedicated phone lines and a microwave link, and the two signals traced out by Easterline-Angus strip chart recorders, frequently in red ink. Weber, secretary Alessandra Esposito, and others (including me at one stage) then examined the charts, looking for times when both outputs had been above some pre-chosen threshold for a fraction of a second. The numbers varied over the years. The first bar was resonant at about $1400 \mathrm{~Hz}$, the later ones and the disk (in its "breathing" mode) at 1660 or $1661 \mathrm{~Hz}$.

Over the next few years, groups at Stanford, Saskatchewan, Glasgow, Louisiana State, Rochester, Rome, Moscow State, the Max Planck Institute in Munich, Caltech, Bell Telephone Labs, the University of Tokyo, and IBM built resonant bar detectors, generally just one per site and not run together for coincidences. None reported results consistent with the Maryland experiments, and all at some stage announced that Weber's data were just noise of some sort. It is not true that none of the Maryland results were ever confirmed (next section), but that was the impression left in most physicists' minds.

Numerous changes in the Maryland installations also occurred over the years, many generated in-house, some in response to assorted criticism. First the data were recorded separately at the two locations, and data tapes flown back for computer analysis by programmer Brian Reid (whose name appears as Reed in some secondary sources), lest the phone lines somehow be the cause of the coincident power pulses. The crystals were replaced with brass mushroom-shaped transducers fastened to the far ends. Super-conducting quantum interference devices (SQUIDs) were tried as coupling. Preferred and non-preferred algorithms for deciding what constituted a coincidence were implemented by several students as data experts. And so forth, as we all slipped gradually into the situation described in Section 8.

One part of the procedure the current interferometer community agrees Joe got right. The rate of accidental, noise-based, simultaneous increases in power output from two bars was measured by inserting time-delays into one of the data streams. A plot of the number of coincidences vs. time delay was expected to show a peak at zero, as indeed such plots (e.g. Fig. 5) very frequently did. Much later, the same technique was used to decide whether there were really time coincidences between gamma ray bursts and power peaks from the bars. Again the answer was frequently yes (Fig. 6). I entered the picture briefly at that point by suggesting that the programmer might also try running the program with a deliberately wrong time for the GRB, in case something in the time-shifting process accidentally enhanced count rates. If this was ever done, I did not see the result.

The largest mass detector then and now was the earth, and it was instrumented to look for excitation of its normal modes by passing gravitational waves (Forward et al. 1961). The upper limit was actually low enough to be able to say that gravitational radiation at periods of 5-20 min did not close the universe. The detectors did, however, see the 54 min "gravest normal mode" of the earth and a few others after a devastating Richter 9.5 May 1960 earthquake in Chile.

One of the referees has asked for my "take" on the process by which Joe Weber was "voted off the island". This has been addressed by science writers (Bartusiak 2000), historians of science (especially Franklin 1994, 2010), a sociologist (Collins 2004, 2011), speakers at conferences on relativity and gravitational radiations (e.g. Shaviv and Rosen 1975), and websites (Aufmuth, accessed spring 2016, is particularly unpleasant, partly because Weber is represented by a single, unflattering photograph, 


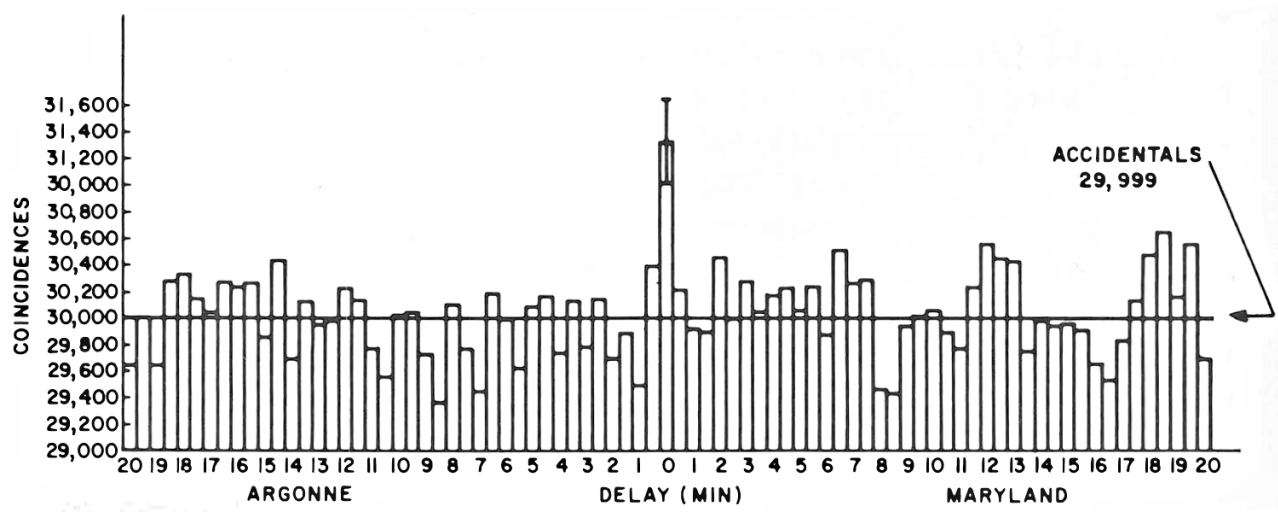

Fig. 5. Time delay histogram, giving coincidences vs. time delay for continuous operation of the Argonne and Maryland bars, August 3-October 17, 1974. Bins are 0.1 seconds wide (despite the coordinate label). From Weber (1980), on p. 458.

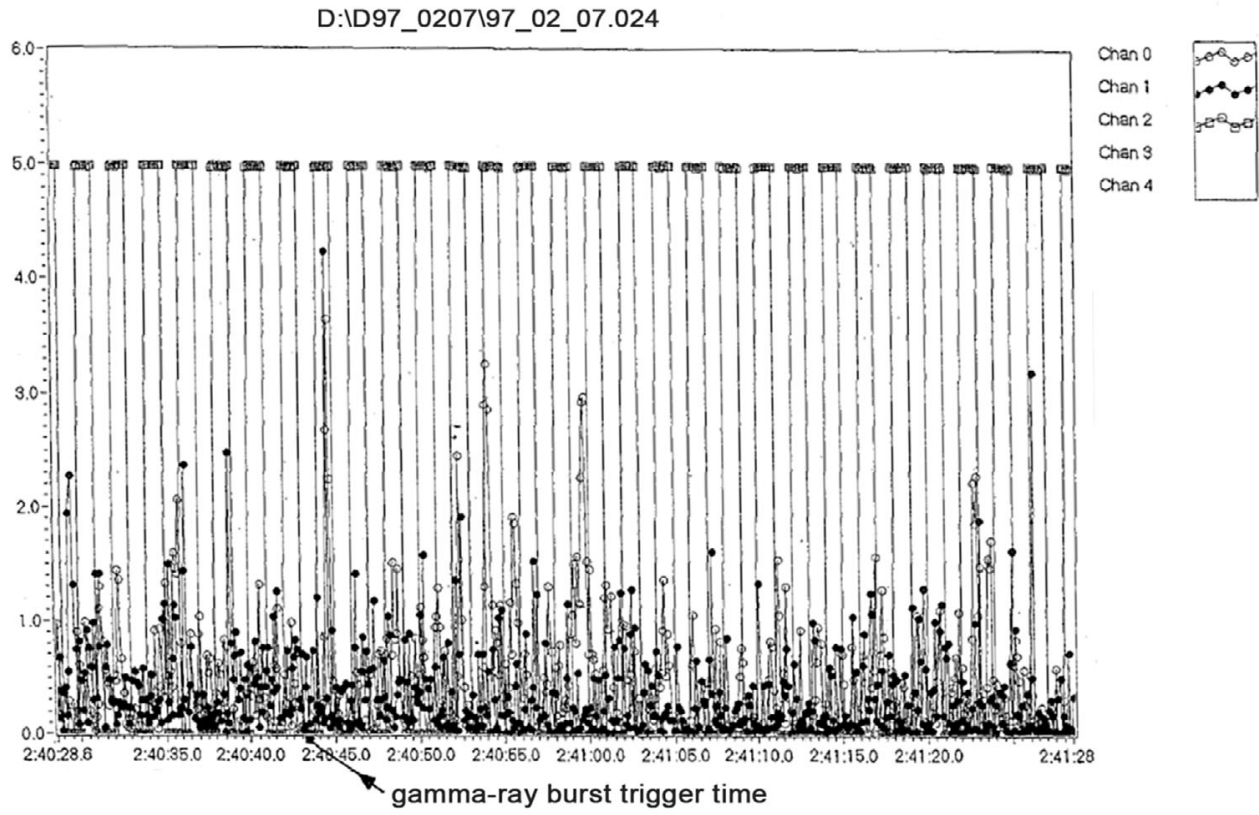

Fig. 6. Plot of output of two bars (shown as filled and open circles) for about one minute around the trigger time of a gamma ray burst. From an overhead transparency in Weber's files at the time of his death. Data analysis related to Weber and Radak (1996).

while all the other groups move forward with flattering ones). I am obviously not the right person to ask. No one wants "a critic on the hearth" (Joe built beautiful fires, by the way, and could also drive large trucks as well as ships and carrier-based aircraft). I have three specific memories of that 1974 GR7 conference in Israel: (1) the sight of a dead camel by the road; (2) incoming GRG president Nathan Rosen getting off the tour bus and helping the driver to change a flat tire; and (3) an incident outside the church of the nativity in Bethlehem that led us to say that the outgoing president of GRG was "the sort of person who would give you the coat off his back, but reluctantly". That we were not all friends and would soon be even less so was not 
my dominant thought, but rather how lucky I was to be married to someone whose work had spawned so much interest and who could still communicate freely with older Israelis in Yiddish. Our next trip to Israel was for the 1975 Texas symposium, where we met conductor Zubin Mehta and the mayor of Jerusalem, Teddy Kollek.

\section{The lunar surface gravimeter}

The highpoint, at least financially, of the 1960s and early 1970s was the Lunar Surface Gravimeter, NASA and other funding for which took care not only of equipment purchase and construction, Weber's summer salary and travel, his student/postdoc group and technicians, but also some theoretical students working with other advisors at Maryland.

NASA had wanted a scientific component for the Apollo program from the beginning. Rock samples were an obvious part of this, and their composition contributed to the current "best buy" model of lunar formation. The most clearly productive aspect was the installation and later upgrade of a lunar corner reflector, which has permitted more than 45 years of nearly continuous monitoring of the moon's distance, during which that distance has increased at 3-4 centimeters per year, owing to tidal drag (which also slows the earth's rotation). The proposal for the LSG (whose design was somewhat inspired by the device used to look for triggering of the earth's normal modes) was a response to a request for proposals for Apollo science. The intent was to turn the moon into a gravitational wave detector, with the LSG responding to triggering of the moon's normal modes by passing gravitational waves.

What is the difference between a seismometer and a gravimeter? A seismometer (earthquake detector) is supposed to be driven by solid-body (electromagnetic) forces from its supporting structure. An early Chinese one had a ring of dragon heads around a vase holding jade balls in their mouths. When the device was shaken by a quake wave, a dragon dropped his ball, and his location in the ring indicated the direction from which the wave had come. A gravimeter, in contrast, is isolated as much as possible, by acoustic and electromagnetic filters, from the underlying substrate, and is supposed to respond to changes in local $\mathrm{g}$ (which is $9.81 \mathrm{~m} / \mathrm{s}^{2}$ on the surface of the earth).

The earth-based device had used a La Coste - Romberg sensor with the instrument package assembled by Jerome V. Larson (of the EE department) and Weber. The sensor was a mass, spring, and lever system with a period of 20 seconds. It was critically damped and temperature controlled near $50{ }^{\circ} \mathrm{C}$, at which the first derivative of the force constant with respect to frequency vanished. A capacitor plate attached to the mass served as an element of an AC bridge. If local g changed, the mass was accelerated and the bridge became unbalanced, resulting in an error voltage. This voltage was amplified and used to restore the mass to its equilibrium position by means of a closed-loop servosystem and electrical forces. The measured output voltage was recorded and computer-analyzed to look for the frequencies of the earth's normal modes. This device worked as designed (Weber and Larson 1966).

Under NASA rules, however, the LSG had to be built by American industry. Bendix corporation was the contractor selected, and Weber, as PI, was not allowed to touch the construction process. Sadly, the LaCoste - Romberg sensor was assembled with a misunderstanding of the value of $g$ on the moon (it is NOT $9.81 \mathrm{~m} / \mathrm{s}^{2}$, which is why Apollo astronauts could leap tall buildings at a single bound). The LSG was emplaced by Apollo 17 astronauts (the last team). Data were multiplexed with other Apollo 17 ALSEP instruments and sent to Earth stations, recorded on "range tapes", from which NASA employees extracted the data for each separate experiment and turned it over to the PIs. 
It was almost instantly obvious that something was wrong, which rendered the channels with tidal data and free mode data almost useless. But the high frequency seismological data could still be used after the beam was rebalanced by a command radioed from earth to the instrument, though this changed the resonance characteristics of the detection mechanism.

At this point Mr. Russell L. Tobias (from whose account, Tobias 2013, this material is largely taken) joined the team, with the task of analyzing what was coming from the LSG and looking for coincidences with output from the College Park bars. The 7-track tapes were difficult to read, and Tobias with a representative from Lockheed Electric Company managed to improve NASA's tape drive maintenance procedures. Other people involved were John Gigante, an electrical engineer, Bruce Weber, a data technician, and several electronic technicians contracted through Pulse, Inc, including Ms. Pota Fitzgerald, and the senior programmer, Brian Reid, who left to earn a graduate degree in computer sciences elsewhere.

The university of Maryland's central Univac 1108 computer system was inadequate for the data processing, and NASA provided a dedicated DEC PDP-11. Joe regarded that computer as dubious, and described NASA's reclaiming it as analogous to the story "The Ransom of Red Chief" 5 . Russell, however, spent a final, successful all-night session with it and managed to accumulate enough processed data for his thesis, which focussed on the comparison between lunar acceleration and the aluminum bar events.

Any number of footnotes could be added to this tale, of which I pick out two. First, Russell was already reasonably certain he was not aiming for a career in academe. He has been a successful member of private industry throughout the interim. The second is that his father and Joe Weber had been lab partners during their freshman year at Cooper Union (1935-36), though the event apparently did not leave very happy memories on either side. The senior Tobias completed a degree in chemical engineering in 1939 and a masters at Brooklyn Polytechnic, but did not complete a doctorate at George Washington University. He invented an early form of artificial rubber used by soldiers during WWII but Joe, of course, was in the Navy.

I suppose there is at least one other lesson from the LSG 1969-present tale. With modern (2013 not 2023!) search techniques, someone with an unusual name is much easier to find that someone with a common one. I located Russell within 24 hours of deciding to try to find him for the NASA studying-old-moonquakes project, but there are several other Joseph Webers to be found trolling compilations of physics papers, including one who works on gravitational radiation. Idle browsing of my own name brought up six different obituaries of women named Virginia Trimble, none of them, fortunately, mine, though one had lived in Kissimmee Florida, where I was about to go that day.

Incidentally, although Joe Weber is generally now perceived as having been a rather solitary person, and a very large fraction of his papers are single-author, the 1980 overview thanks 22 people for contributions to the design and construction of the experiments, data analysis, and helpful discussions. Scanning other sets of acknowledgements, co-authors, and my own memory brings that total up to something like 45 or 50. Of the pioneering groups, Robert Forward died in 2002; David Zipoy is apparently living in retirement in Florida; and I have no idea what became of most of those involved in the project, but the most faithful was Darrell Gretz, the technician who was the last person to drive Joe from the Chevy Chase house to the Gravity Building and back (except for me) as he was dying. It is perhaps not totally irrelevant

5 "Red Chief" was a small boy whose parents had found him so tiresome that, when he was kidnapped, they declined to pay the ransom. The kidnappers found him so tiresome they eventually paid the parents to take him back. 
that our annual parties (1973-91) on each coast tended to attract about 100 people each, a large fraction of them scientists, and, of course, significant others.

\section{The aftermath}

For a period of about ten years, the relativity, physics, and other scientific communities expressed very considerable interest in Weber's work. This was manifest in an enormous number of invitations to give talks at conferences and in physics departments and in invitations to write review and scientific articles. The award of the First Prize in the essay competition of the Gravity Research Foundation (Weber 1959a) came at the beginning of this period, and the Babson Award (1970) from the same Foundation $^{6}$ and the Boris Pregel Prize of the New York Academy of Sciences for research in physics and/or astronomy (1973) near the end of it. In between came his 1971 election to the International Committee on General Relativity and Gravitation, which would become the governing body of the International Society on General Relativity and Gravitation in 1974. A highlight of the 1971 (Copenhagen) meeting in my mind came when the Russians stood up together and walked out of the business meeting, because they had received their visas as scientists not as voters.

I realize now that I actually witnessed the transition from general interest to widespread distrust. Weber gave an invited talk on his results from the operation of a widely-separated pair of "Weber bars" at that 1971 Copenhagen meeting (GR6). After his presentation, a group of young postdocs from the Institute of Theoretical Astronomy in Cambridge tried to figure out what might be going on. He had reported the events as having come from the general direction of the galactic center, but bar detectors have a front-back symmetry, so that the pulses could have been coming from the opposite direction, which is very close to the direction to the Crab Nebula with its active pulsar. We had intended to ask him the next day for some details of the frequency response of the bar, on the grounds that the Crab pulsar, as it slowed, might be passing through a submultiple of the bar frequency. The question never got asked, because Anita Straus Weber had died that day, and Joe took off immediately from Copenhagen to return to the US.

At the 1970 Texas Symposium on Relativistic Astrophysics in Dallas, he described an additional detector, a massive aluminum disk (Fig. 7) whose radial "breathing" mode would be excited if gravitational waves had a dipole component. This is zero in general relativity, but might have been $7 \%$ or so of the quadrupole power if the Brans-Dicke (1961) scalar-tensor theory of gravitation had been correct $^{7}$.

Weber's invitation to give an endowed lecture at the University of Southern California in early February 1972 was also near the transition point. This was the occasion for our first real meeting (which led to marriage on 16 March 1972). I participated in a small fraction of the data processing over the next couple of years.

By the time of the 6th Texas Symposium (December 1972 in New York), it was clear that portions of the community were no longer supportive. Joe thought it might moderate the hostility of his critics if I gave the presentation for the group (Trimble and Weber 1973). This, to put it mildly, did not happen (Weber et al. 1973,

\footnotetext{
${ }^{6}$ Roger Babson regarded gravitation as an obstacle to be overcome, and his foundation was originally aimed at anti-gravity. This hasn't happened so far, though the annual prize essay competitions continue, and the cash prizes have come at useful times for some of the winners, like the young Stephen Hawking (Kaiser 1987).

7 The situation was typified by a then-young, very bright (now distinguished and retired) strong supporter of GR who remarked to me that he could see where Dicke was wrong, but Weber had him worried.
} 


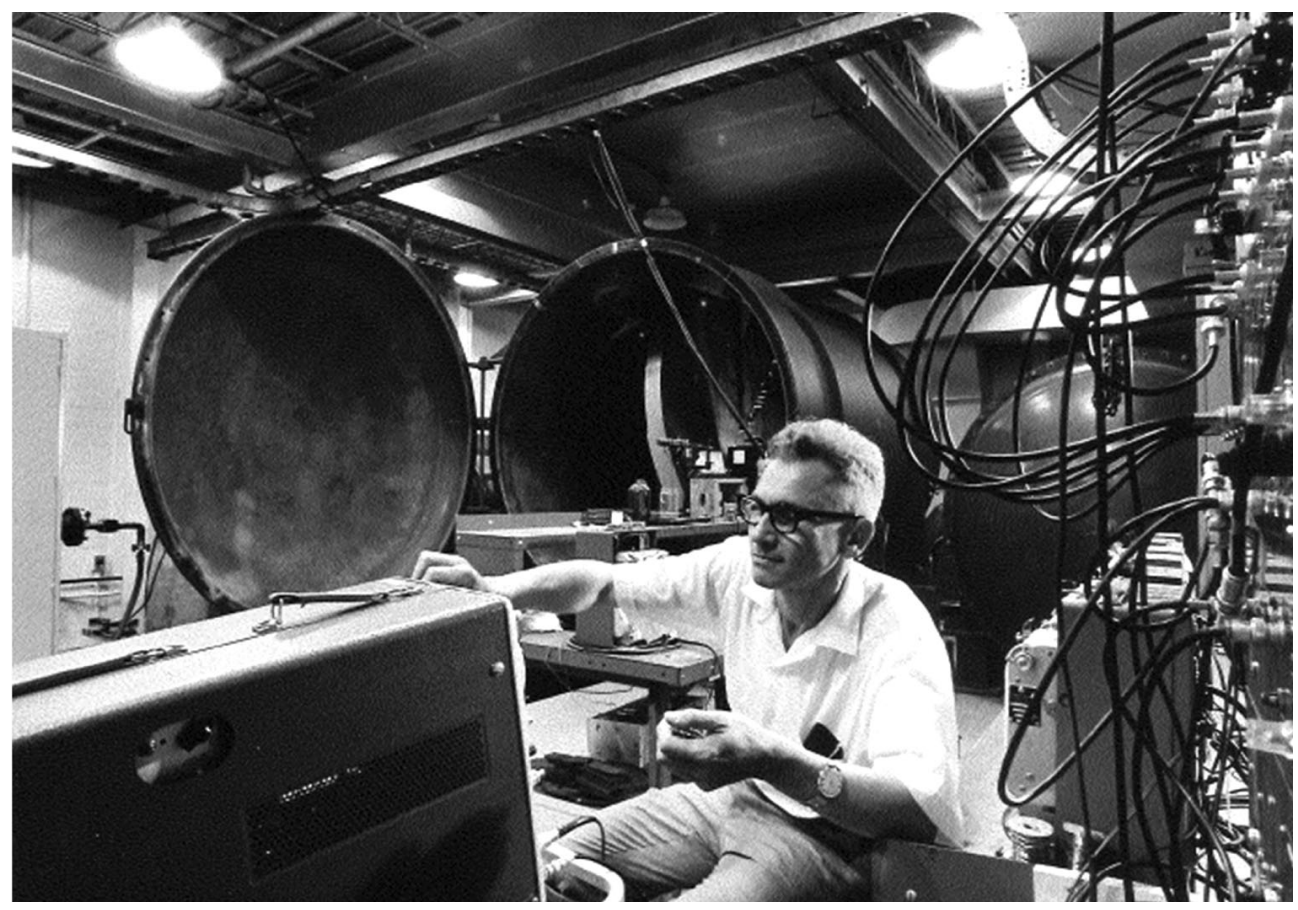

Fig. 7. Foreground: Weber with archaic imaging device; Background: the disk antenna in an open vacuum chamber.

Tyson 1973). It was then 30 years before I gave another invited "Texas" talk, and before the topic of gravitational radiation made it back into the plenary program (Schutz 2003), though there had been parallel sessions on the topic in the interim. Peter Bergmann had just died (October 19, 2002) at the time of that 21st Texas Symposium. Schutz did not cite Weber, and his name got a laugh when I responded to a questioner, who had said that something in my talk about X-rays from supernovae was "controversial", "You don't know what controversial means unless you've been married to Joe Weber for 28 years" (Trimble 2003, also my first time back on the Texas program in 30 years).

Joe was, of course, not unaware of the changing intellectual climate. It was probably fall, 1974 when he walked into the dining room, saying "Poor Sweetheart! Her husband thinks he's discovered gravity waves and sold the idea to Howard Hughes for a lot of money!" Grin. Check held up. It was $\$ 15,000$, which was then a good deal of money. It was divided equally, at Joe's decision, among him, Bob Forward, and Dave Zipoy, then in the Maryland astronomy program. Forward was at Hughes, and had arranged the sale of the patents with the idea that a rotating quadrupole, operated in the near-field mode, might detect underlying oil deposits of lower density than the surrounding rock.

In the period $1965-75$ or thereabouts, when Joe was asked to give very large numbers of colloquia, seminars, and conference talks, he developed a "tour" version. I first heard it at USC in February 1972 and again at UCI in early March that year. Anonymous referee II remembers a 1975 version at Louisiana State University as "one of the most memorable seminars I ever attended" (Well, we were all a good deal younger then). Weber would start with the Einstein metric and go very quickly from memory, through the Christoffel symbols and on to the Riemann and Ricci 
tensors and then the quadrupole formula for emission by a pair of orbiting masses, $M$, in a form like

$$
L=\frac{32 G}{5 c^{5}} \omega^{6} \mu a^{2}
$$

where $\mu=$ reduced mass, $\left(M_{1} M_{2}\right) /\left(M_{1}+M_{2}\right), a=$ separation of the pair, and $\omega$ $=$ their angular frequency. He called attention to the $G$ upstairs and $c^{5}$ downstairs, suggesting that the resultant emission must be very weak, but then, again quickly and from memory, replaced the separation, $a$, by two Schwarzschild radii and the $\omega$ by the angular frequency of two star-sized masses at that separation. Magically, $c$ came upstairs and $G$ downstairs, and, the speaker suggested with a broad grin, the power emitted might not after all be so very small.

The referee supposed that the idea of using Schwarzschild radii (that is, a binary black hole) came from John Wheeler, during one of Weber's visits to Princeton. Impossible, of course, to prove a negative, but I think perhaps not, Weber (1961a) has roughly the Landau-Lifshitz (1951) version of equation (1). And in a review (Weber 1980) he thanks J.R. Oppenheimer and F.J. Dyson for encouragement during his 1962-63 stay and cites Dyson (1963) for the formula. It is necessary to distinguish "black hole" in the sense of something whose size is essentially its Schwarzschild radius and the singularity or whatever else might be going on at the center. Weber said frequently that he did not think singularities occurred in nature and that Einstein, if he had realized that GR predicted such singularities, would have abandoned the theory.

But the first search for "frozen stars", meaning ones at their Schwarzschild radii, was the work of Zeldovich and Guseinov (1966). That normal binary evolution could produce such systems was well known by 1971 (Paczyński 1971). The first observed black hole accretor, Cygnus X-1, dates from 1972, and Joe was actually a co-author on a 1973 paper (Trimble et al. 1973) that tried to push the accretor mass down into the neutron star range. Weber and Zeldovich had a warm relationship that dated back at least to the Warsaw GRG.

As community doubts grew, the funding climate, of course, also changed. NSF support dropped to $\$ 50000$ per year in 1975 , the same time frame in which the agency began supporting the project that became LIGO. Some years, increasingly, it was zero. Late dollar pulses came for an attempt at cryogenic bar detectors, whose noise should, of course, be much smaller. The one at $\mathrm{He}^{4}$ temperature (near $4 \mathrm{~K}$ ) ran briefly, but experienced noise from the boiling helium. Other groups attempted indium-plated aluminum, which crackled, and pure indium when struck goes thud, not ring. A helium dilution refrigerator, intended to bring the operating temperature down to milli-Kelvin, never worked properly. The manufacturer eventually took it back. And $\mathrm{He}^{3}$ is one of the most expensive substances on earth. A presentation on "Development of cryogenic gravitational wave antennas at the University of Maryland" was given at the 8th International Conference on General Relativity and Gravitation in Waterloo Canada on August 10, 1977. The authors were listed as W. Davis, D. Gretz, J.P. Richard, and J. Weber (who actually gave the talk). Proceedings were never published.

The morning we were to leave for the meeting, the airline phoned to say that Canadian air services were on strike and we would be dropped at Rochester NY. Joe instantly phoned the airport there, reserved nearly the last rental car available. We flew, landed, drove across the border, and were in time for the opening reception (always the best part of a conference, I think). GRG's host there was Werner Israel, who under the previous GRG rubric would have become president of the society in succession to 1974 host Nathan Rosen, for the next three years, but declined the office, which has since been an elective one. We even saw Niagara Falls.

Still later, NASA-Goddard provided some funding for Weber to look for coincidences between bar events (the two large ones were by then long since both 
in the gravity building) and gamma ray bursts, whose extra-galactic character had not yet quite been established. The funding was primarily for the support of a postdoc, Bronislav Radak, borrowed from the high-energy group, to process the data, with the understanding that he knew very little about general relativity or the purposes of the experiment, and so could do the processing in a truly blind fashion (S. James Gates 2016 email personal communication). Coincidences between bar pulses and GRBs were reported by Weber and Radak (1996) covering the period 1990-91 (Fig. 6).

\section{Neutrino detectors and a new cross section for bars?}

Meanwhile, however, a (probably) well-meaning colleague set Weber off in a rather different direction. It was spring (about 1980) because we were in California, visiting Caltech for a colloquium or something and lunching in the mostly-student cafeteria variously called Chandler Dining Hall and "The Greasy" (much less so than when I was a grad student there in the 1960s). At the same table were a couple of physics graduate students and Richard Feynman. Joe was trying to explain something about how he thought the bar detectors worked. Feynman, characteristically impatient, said something along the lines of "oh, why don't you give up on gravitational waves; go look for neutrinos or something".

Joe took this as serious advice (I don't know that it wasn't), and started thinking back to single, large, perfect crystals, like pink ruby, quartz, sapphire, and silicon for bars of inches rather than feet. The idea was that they might scatter in an analogy to Mössbauer scattering of gamma rays, that is, recoiling as a whole, but with an interaction cross section that was proportional to the number of dipoles among the atoms or molecules. Weber $(1981 \mathrm{a}, 1984,1985 \mathrm{~b})$ are discussions of the theory. An early referee reported that he couldn't prove the analysis was wrong and that Weber seemed to have invented s-matrix theory by a non-standard method. Joe then went back and did the calculation in standard notation, getting the same answer.

Neutrino sources used included tritium in titanium tritide $(12 \mathrm{keV})$, reactors at both UC Irvine and the National Bureau of Standards (now NIST, 1.6 Mev), and the sun (0-430 keV). Results appear in many conference proceedings, but Weber (1984) is the easiest to access. It describes the detectors in detail. All are torsion balances such that a deflection unbalances a radio frequency bridge. That signal is amplified, used to restore the balance to rest position, and recorded as the signal (Fig. 8). The tritium and solar experiments took place inside a wood building, with extra seismic and EM shielding, and extra temperature control, inside the Gravity Building. The tritium case used two 13-gram (65 carat) colorless, clear sapphire crystals, and the source was cycled back and forth in front of the balance. In the reactor case, a larger sapphire was used as a shield some of the time, and it indeed seemed to block the neutrinos. The solar case was in effect an Eötvös experiment, because the torsion balance had one mass of sapphire and one of lead, and was seen to twist in time with the direction to the sun being aligned perpendicular to the face of the crystals.

The paper cites standard texts (Compton and Allison on Nuclear Physics, Jackson on E\&M, Yang and Lee on weak interaction physics, Feynman and Hibbs) and also specific contributions by Lamb, Mössbauer, Eötvös, Dicke, and Braginsky (who was also one of those who built a bar detector and remained friendly). Individuals thanked include Gregory Wilmot, the programmer, Larry Spruch and Syd Bludman for theoretical advice, Ray Davis of the original solar neutrino experiment for inspiration, Frank Desrosier, John Giganti, and Jay Kimbell for constructing the apparatus and electronics. Funding had come from the NSF, DARPA, the Defense Nuclear Agency, and the Strategic Defense Initiative (Star Wars) Office of Innovative Science and Engineering. The defense connection was the possibility of using small, portable neutrino (or anti-neutrino, they were the same for this experiement, as were all three flavors) 


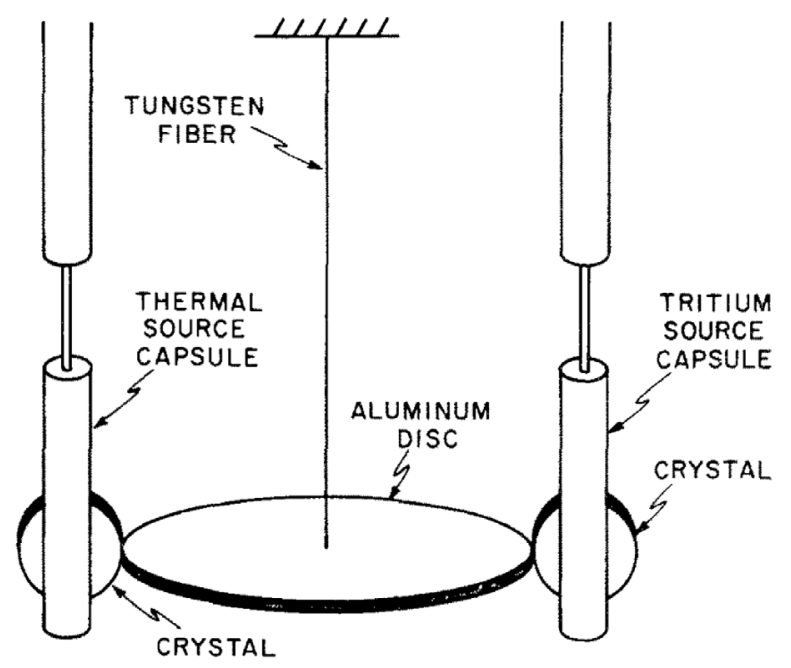

Fig. 8. Design of the neutrino detector used with a titanium tritide source. Because the expected force on the right hand crystal from the neutrinos pushing out would be nearly equal and opposite to the gravitational force, the dummy on the left was made to have equal mass and to radiate as much heat as would the decaying tritium. The two source capsules were lifted up and down together in cycles of several minutes, halting at the top and opposite the crystals. A radiofrequency bridge became unbalanced whenever the torsion balance twisted. The unbalance voltage was amplified and both recorded as the signal and used to restore to balance to its equilibrium position. The whole thing was, of course, enclosed in a vacuum chamber, maintained at about $10^{-6}$ Torr. From Weber (1984), on p. 1197.

detectors to locate nuclear submarines from above the ocean. The tritium sources proved to have half-lives much less than 12 years (counted in the lab and as neutrino sources). The electrons from a few decays (which did not get out of the shielding) heated the $\mathrm{H}^{3}$ gas which expanded until the capsule leaked (Weber 1984).

More proposals went in, some with my name suggested as co-investigator. Joe had by then passed 70 and, under the rules of the time, been forced to retire. But, once again, funding and interest from the community dropped more or less to zero, though in 2002, a couple of scientists from Pirelli Tire Company came to Maryland and took away many pounds of neutrino detector equipment. I secretly kept one small pink ruby and one PZT crystal from the bar detector era as souvenirs. Other sourvenirs? Well there was an even larger clear, but not colorless crystal that Joe said had been intended for an engagement ring for an elephant, but ended up as a pendent for me. And as a result of the "Star Wars" connection, I got to dance a Viennese waltz with Eugene Wigner, a claim very few full professors of physics can make.

Weber (1989 and many other conferences) came to think that some similar coherent scattering process might enormously enhance the cross section for the bar detectors for gravitational waves, accounting for his positive results and the negative ones from groups that tried different arrangements. The various neutrino experiments had yielded signals very much like the calculated ones, so why shouldn't the bar detectors?

And then along came Supernova 1987A (A because it was the first found that year, not because of its importance). At the moment the neutrino and electromagnetic signals started reaching earth on February 23rd, none of the better-supported cryogenic or other bar detectors were up and running, so there were records only from the two at Maryland and one at Rome. Results appeared mostly in conference proceedings (Weber 1988b, 1990, 1994 is only a subset), and, worse luck, the gravitational 
radiation pulses were time-coincident not with the universally-accepted burst of neutrinos recorded at Kamioka and at IMB (and probably also at Baksan), but with the 5 neutrino-like events recorded by the Mt. Blanc detector about 5 hours earlier. A few theorists at the time attempted two-stage super-nova models, for instance collapse first to a neutron star and then to a black hole (see Trimble 1988 for many early references), but once again interest quickly waned. I cite here only Amaldi et al. (1988) to clarify that the Italian involvement had originally included a very high profile physicist.

After 30 September 2000, I received very many expressions of sympathy from physics and astronomy colleagues; one from a member of the Rome group (who would I imagine now prefer to remain anonymous) said that they were again finding a correlation with the galactic center and would be announcing this soon. I don't think they ever did, but see Galeotti and Pizzella (2016) on SN 1987A results.

What became of everything? The two largest bars remained on-line in the Gravity Building until Joe died; the last data tape ran out a day or two later. One of the bars is now in an exhibit at the Hanford site of the LIGO detector. I gave a colloquium talk there at the time it was dedicated. The original baby bar was given to the Smithsonian for an Einstein centenary exhibit in 1978. It is probably still somewhere in their storage room. Three other bars are still in storage at the University of Maryland, thanks to the kind offices of Lorraine DeSalvo, who is considering that they might be made into some sort of large art object. The disk antenna, hundreds of data tapes, and decades of bound notebooks presumably found their way into recycling. The last notebook was in the Gravity Building, about half full, and recorded the last year or so of measurements of the equivalent noise temperatures of the bars, which had gradually climbed as the cement holding the crystals on aged and cracked.

Coming down almost to the present, in May, 2014 Akira Banchi, associated with the Japanese TV organization NHK, wrote asking my permission to use some film footage of Weber working on one of the bars, taken in the early 1970s and used in a 2005 NSF documentary. I have not seen either the documentary or what NHK did with the footage, but of course I gave permission.

Logically last, though not quite chronologically, the Lunar Surface Gravimeter had a sort of afterlife. In 2013 and 2014 I heard from an Apollo ALSEP Missing Data Focus Group, involving people at NASA, Univ. of Colorado, Univ. of Maryland, Rice, UCLA, the University of Arizona Lunar and Planetary Lab, Texas Tech, MIT, and elsewhere. They were attempting to recover as many as possible of the original data tapes from experiments in the Apollo Lunar Science Experiment Packages, of which the LSG had been one in the last, December 1972, Apollo 17 flight. A happy outcome of this for me was reconnection with Dr. Russell Tobias, who, as a Maryland graduate student, had taken primary charge of analyzing the LSG tapes up until the time funding was withdrawn and who also prepared the final report on the project. Some of the information he provided appears in Section 6.

\section{Gravitational waves today}

The official announcement of the first event detected by LIGO came while I was writing this and is to be found as Abbott et al. (2016). A number of other papers are in press, on arXiv, or in preparation; a second event is being discussed by official LIGO speakers at conferences and colloquia; and a third is rumored. I was present at the official NSF 11 February LIGO press conference, at the kind invitation of NSF director Dr. France Cordova, a friend since she was a graduate student at Caltech. Press coverage was, of course, widespread, in Nature, Science, and all the rest. My favorite 
discussion was that of Bartusiak (2016) because she mentions Weber's work with reasonable charity, as she did in her book (Bartusiak 2000).

All the relevant conferences (and some not so relevant ones) and very many department colloquium series are arranging LIGO talks. This time, there are 1004 collaborators to share the task, well perhaps only 1001, because the initial paper includes three authors who died before publication. In fact, even I have been asked to give a few talks, and I was asked on very short notice to provide a nomination of LIGO folks for a foundation prize a few days before the prize committee was to meet. They won, with the three leaders I had suggested to the fore; and have since won at least three additional major prizes with the same three people on top. Some of the information needed to make Ronald Drever part of the lead trio came from Collins (2004).

Many groups are tooling up or activating earlier plans for "multiwavelength astrophysics", that is, attempts to locate electromagnetic, neutrino, or cosmic ray counterparts for GW bursts. Indeed I am part of one of these groups, the "transient and variable source working group" for the Large Synoptic Survey Telescope. But I am still a widow and still miss beyond words our daily "after breakfast hug" and the voice caroling out as steps ascended the stairs, "I wish to announce my safe return!"

Acknowledgements. I am indebted to Drs. Robert L. Forward and Vera Cooper Rubin for, respectively, professional and personal introductions to Joseph Weber, to Dr. Russell Tobias for his account of the Lunar Surface Gravimeter, to Dr. Fred M. Johnson (a Townes student at Columbia) for some details of the maser project there, and to the editorial board of EPJH for the invitation to compile this well-timed history. The editors of the special issue, referee Allan Franklin, and anonymous referee II (hi David!) contributed some important missing references (or requests for them!) and other useful information. MPIWG student Bendix Düker very bravely and very expertly turned a scruffy typescript into the well-formatted article you see before you. Joe and Anita's granddaughter Dr. Elizabeth Weber Handwerker located school annual pages and other information about her grandparents for which I am grateful. My deepest debt is, of course, to Joseph Weber, truly as the Navy says in bestowing commissions, an officer and a gentleman, and my best friend for more than 28 years.

Note added in proof. On 1 November 2016, Prof. Jayanth R. Banavar, Dean of the University of Maryland College of Mathematical, Computational, and Natural Sciences, organized there a gravitational waves festivity. Of the old gang, at least Darrell Gretz and John Giganti were there, alive and well. My talk (the previous day) was an abbreviated version of this paper. Darrell has recently written up his memories of the years working with Weber and is of the opinion that the bar detectors were responding to some real physical phenomenon.

\section{References}

Abbott, B.P. et al. 2016. Observation of Gravitational Waves from a Binary Black Hole Merger. Phys. Rev. Lett. 116: 061102-1-061102-14.

Adler, R.J., H.J. Bazin and H. Shifter. 1975. Introduction to General Relativity, 2nd Ed. McGraw Hill.

Amaldi, E., P. Bonifazi, S. Frasca, M. Gabellieri, D. Gretz, G.V. Pallottino, G. Pizzella, J. Weber and G. Wilmot. 1988. Analysis of the data recorded by the Maryland and Rome room temperature gravitational wave antennas in the period of the SN 1987A. In M. Kafatos and A.G. Michalitsianos, eds. Supernova 1987A in the Large Magellanic Cloud, Cambridge University Press, Cambridge, pp. 453-462.

Anonymous. 2016. The Economist, 13 February, p. 77.

Aufmuth, P. http://www.geo600.uni-hannover.de/ aufmuth/JoeWeber.pdf ("Joseph Weber 1919-2000 Offizier \& Gentleman") accessed October, 2016.

Bartusiak, M. 2000. Einstein's Unfinished Symphony. Joseph Henry Press, Washington, DC. 
Bartusiak, M. 2016. The long road to detecting gravity waves. Science News 189: 24-27.

Basov, N.G. and A.H. Prokhorov. 1954. Application of molecular beams for radiospectroscopic study of molecular rotational spectra. Journal of Experimental and Theoretical Physics 27: 431-438 (the page numbers are different in the English translation).

Bergmann, P.G. 1962. Allocution de Cloture/Summary of the Colloque International de Royaumont. In Lichnerowicz and Tonnelat (1962), pp. 463-471 in English, 451-462 in French.

Bertolotti, M. 1983. Masers and Lasers: An Historical Approach. Adam Hilger, Bristol.

Blum, A.S., R. Lalli and J. Renn. 2015. The Re-invention of General Relativity: A Historiographical Framework for Assessing One Hundred Years of Curved Space-time. ISIS 106: 598-620.

Bloembergen, N. 1956. Proposal for a new type solid state maser. Phys. Rev. 104: 324-327.

Bondi, H. 1957. Plane gravitational waves in general relativity. Nature 179: 1072-1073.

Bondi, H. 1962. On the physical characteristics of gravitational waves. In Lichnerowicz and Tonnelat (1962), pp. 129-135.

Bondi, H. 1965. Some special solutions of the Einstein equations. In A. Trautman, F.A.E. Pirani, and H. Bondi, eds. Lectures on General Relativity. Prentice Hall, Englewood Cliffs NS, pp. 375-489.

Bondi, H. and W.H. McCrea. 1960. Energy transfer by gravitation in Newtonian Theory. Proceedings of the Cambridge Philosophical Society 56: 410-413.

Bonnor, W.B. 1957. Non-singular fields in general relativity. J. Math \&3 Mech. 6: 213.

Bonnor, W.B. 1959. Spherical gravitational waves. Phil. Trans. Roy. Soc. A 251: 233-271.

Brans, C. and R.H. Dicke. 1961. Mach's principle and a relativistic theory of gravitation. Physical Review 124: 925-935.

Brill, D. 1959. On the positive definite mass of the Bondi-Weber-Wheeler time-symmetric gravitational waves. Annals of Physics 7: 466-483.

Cameron, A.G.W., ed. 1963. Interstellar Communication. Benjamin Press, New York.

Campbell, C. 1960. The design of a two-level solid state maser. Ph.D. Thesis, Univ. of St. Andrews.

Collins, H. 2004. Gravity's Shadow. Univ. of Chicago Press, Chicago.

Collins, H. 2011. Gravity's Ghost. Univ. of Chicago Press, Chicago.

Damour, T. 1987. The problem of motion in Newtonian and Einsteinian gravity. In. S.W. Hawking and W. Israel, eds. 300 Years of Gravitation. Cambridge University Press, Cambridge, pp. 128-198.

Davis, H., D. Gretz, J.P. Richard and J. Weber. 1977. Development of cryogenic gravitational wave antennas at the University of Maryland. 8th International Conference on General Relativity and Gravitation, Waterloo, Canada, August 10, $197 \%$.

Dyson, F.J. 1963. In Cameron (1963), p. 115.

Eddington, A.S. 1923. The Propagation of gravitational waves. Proc. Roy. Soc. A 102: 268282.

Eddington, A.S. 1924. The Mathematical Theory of Relativity, 2nd Ed., Cambridge University Press, Cambridge, sect. 57.

Einstein, A. 1916. Näherungsweise Integration der Feldgleichungen der Gravitation. Preuss. Akad. Wiss. Berlin, Sitzungsberichte der Physikalisch-mathematischen Klasse: 688-696.

Einstein, A. 1917. Kosmologische Betrachtungen zur allgemeinen Relativitätstheorie. Preuss. Akad. Wiss. Berlin, Sitzungsberichte der Physikalisch-mathematischen Klasse: 142-152.

Einstein, A. 1918. Über Gravitationswellen. Preuss. Akad. Wiss. Berlin, Sitzungsberichte der Physikalisch-mathematischen Klasse: 154-167.

Einstein, A. and N. Rosen. 1937. On Gravitational Waves. Journal of the Franklin Institute 223: 43-54.

Einstein, A., L. Infeld and B. Hoffmann. 1938. The gravitational equations and the problem of motion. Ann. Math. 59: 65-100.

Feynman, R.P. 1962-63. Lectures on Gravitation, notes taken, duplicated and distributed by Fernando B. Moringigo \& William G. Wagner.

Fierz, M. and W. Pauli. 1939. Relativistic wave equations for particles of arbitrary spin in an electromagnetic field. Proc. Roy. Soc. A 173: 211-232. 
Forward, R.L. 1971. Multidirectional multipolarization antennas for scalar and tensor gravitational radiation. General Relativity and Gravitation 2: 149-159.

Forward, R.L. 1978. Wideband laser-interferometer gravitational-radiation experiment. Physical Review D 17: 379-390.

Forward, R.L., D. Zipoy, J. Weber, S. Smith and H. Benioff. 1961. Upper limit for interstellar millicycle gravitational radiation. Nature 189: 473.

Foures-Bruhat, Y. 1956. Sur l'intégration des équations de la relativité générale. J. Rat. Mech. Anal. 5: 951-966.

Franklin, A. 1994. How to avoid the experimenters' regress. Studies in the History and Philosophy of Modern Physics 25: 463-491.

Franklin, A. 2010. Gravity Waves and Neutrinos: The Later Work of Joseph Weber. Perspectives in Science 18: 119-151 and references therein.

Galeotti, P. and G. Pizzella. 2016. New analysis for the correlation between gravitational wave and neutrino detectors during SN1987A. Eur. Phys. J. C 76: 426.

Glanz, J. 2000. Obituary of Joseph Weber. New York Times, 9 October, p. A19.

Good, W.E. 1946. The Inversion Spectrum of Ammonia. Phys. Rev. 70: 213-218.

Gordon, J.P., H.J. Zeiger and C.H. Townes. 1954. The maser - New type of microwave amplifier, frequency standard, and spectrometer. Phys. Rev. 95: 282-290.

Gutfreund, H. and J. Renn. 2015. The Road to Relativity. Princeton Univ. Press, Princeton, NJ.

Hartle, J.P. 2003. Gravity. Addison Wesley, San Francisco, CA.

Hirakawa, H. and K. Narihara. 1975. Search for Gravitational Radiation at $145 \mathrm{~Hz}$. Phys. Rev. Lett. 35: 330-334.

Hockey, T. et al., eds. 2014. Biographical Encyclopedia of Astronomers, 2nd Ed. Springer, New York, NY, pp. 823-825.

Homans, J. 2012. Tony Judt: A Final Victory. New York Review of Books, 22 May.

Infeld, L. 1936. The New Action Function and the Unitary Field Theory. Proc. Cambridge Philos. Soc. 32: 127-137.

Infeld, L. 1937. A new group of action functions in the unitary field theory. II. Proc. Cam. Phil. Soc. 33: 70-78.

Infeld, L. 1938. Electromagnetic and gravitational radiation. Phys. Rev. 53: 836-841.

Infeld, L. 1954. On the motion of bodies in general relativity theory. Acta Physica Polonica 13: $187-204$.

Infeld, L. 1956. On equations of motion in general Relativity Theory. Helvetica Physica Acta 29: 206-209.

Infeld, L. 1957. Equations of motion in general relativity and the action principle. Rev. Mod. Phys. 29: 398-411.

Infeld, L. 1959. Equations of motion and gravitational radiation. Ann. Phys. 6: 341-367.

Infeld, L. and R. Michalska-Trautman. 1960. The two-body problem and gravitational radiation. Ann. Phys. 55: 561-575.

Infeld, L. and J. Plebanski. 1960. Motion and Relativity. Pergamon Press, Oxford UK.

Infeld, L. and A.E. Scheidegger. 1951. Radiation and gravitational equations of motion. Canadian J. Math. 3: 195-207.

Infeld, L. and A. Schild. 1949. On the motion of test particles in general relativity. Rev. Mod. Phys. 21: 408-413.

Infeld, L. and P.R. Wallace 1940. The equations of motion in electrodynamics. Phys. Rev. 57: 797-806.

Johnson, F.M. 2016. Personal communication.

Kaiser, D. 1987. Roger Babson and the Rediscovery of General Relativity. In Making Theory and Theorists in Postwar America. Ph.D. Dissertation, Harvard University, pp. 567-595.

Kastler, A. 1985. Birth of the maser and laser. Nature 316: 307-309.

Kennefick, D. 2007. Traveling with the speed of thought: Einstein and the quest for gravitational waves. Princeton Univ. Press, Princeton, NJ, esp. pp. 61-65.

Landau, L. and E.M. Lifshitz. 1951. The Classical Theory of Fields. Addison Wesley, San Francisco, CA, Ch. 11 (and many other editions in many languages). 
Lee, M.D., D. Gretz, S. Steppel and J. Weber. 1976. Gravitational Radiation Detector Observations in 1973 and 1974. Phys. Rev. D 14: 893-906.

Levi-Civita, T. 1917. Realtà fisica di alcuni spazi normali del Bianchi. Rendiconti della Reale Accademia del Lincei 26: 519-531.

Lichnerowicz, A. 1955. Théories Relativistes de la Gravitation et de l'Electromagnétisme. Masson, Paris.

Lichnerowicz, A. and M. Tonnelat, eds. 1962. Theories Relativistes de la Gravitation (Proceedings of the 1959 Royaumont conference) CNRS, Paris.

Loinger, A. 2003. Non-existence of gravitational waves. The stages of the theoretical discovery (1917-2003). arXiv:physics/0312149.

Loinger, A. and T. Marsico. 2016. Email, 6 March 2016.

Marshall, S.A. and J. Weber. 1957a. Plane parallel plate transmission line Stark microwave spectrograph. Rev. Sci. Instrum. 28: 134-137.

Marshall, S.A. and J. Weber. 1957b. Microwave Stark effect measurement of the dipole moment and polarizability of carbonyl sulfide. Phys. Rev. 105: 1502-1506.

Menzel, D.H. 1937. Physical Processes in Gaseous Nebulae I. Astrophys. J. 85: 330-339.

Misner, C.W., K.S. Thorne, and J.A. Wheeler. 1973. Gravitation. W.H. Freeman, San Francisco, CA.

Møller, C. 1952. The Theory of Relativity. Oxford University Press, Oxford UK.

Moss, G.E., L.R. Miller and R.L. Forward. 1971. Photon-noise-limited laser transducer for gravitational antenna. Appl. Opt. 10: 2495-2498.

Paczyński, B. 1971. Evolutionary Processes in Close Binary Systems. Ann. Rev. Astron. Astrophys. 9: 183-208.

Peebles, P.J.E. 2016. Robert Dicke and the naissance of experimental gravity physics, 19571967. Eur. Phys. J. H, Doi:10.1140/epjh/e2016-70034-0.

Peebles, P.J.E., L.A. Page and R.B. Partridge. 2009. Finding the Big Bang. Cambridge University Press, Cambridge, pp. 6 \& 181.

Petrov, A.Z. 1954. Classification of spaces defining gravitational fields Sci. Notes Kazan State Univ. 114: 55-69.

Petrov, A.Z. 1962. Classification invariante des champs de gravitation. In Lichnerowicz and Tonnelat (1962), pp. 107-112.

Pirani, F.A.E. 1957. Invariant formulation of gravitational radiation theory. Phys. Rev. 105: 1089-1099.

Poincaré, H. 1905. Sur la dynamique de l'électron. Comptes Rendus Hebdomadaires de l'Académie des Sciences de Paris 140: 1504-1508.

Purcell, E.M. and R.V. Pound. 1951. A nuclear spin system at negative temperature. Phys. Rev. 81: 279-280.

Richard, J.P. 1976. Sensor and suspensions for a low-temperature gravitational wave antenna. Rev. Sci. Instrum. 47: 423-426.

Robinson, I. and A. Trautman. 1960. Spherical Gravitational Waves. Phys. Rev. Lett. 4: 431-432.

Rosen, N. 1956. Gravitational waves. In A. Mercier and M. Kervaire, eds. Jubilee of Relativity Theory. Helvetica Physica Acta, Supplementum IV, Birkhausen Verlag, Basel, pp. 171175.

Scheidegger, A.E. 1953. Gravitational motion. Rev. Mod. Phys. 25: 451-468.

Schutz, B.F. 2003. LISA and the gravitational wave universe. In R. Bandiera et al., eds. Texas in Tuscany, XXI Symposium on Relativistic Astrophysics, World Scientific, Singapore, pp. 91-102.

Shaviv, G. and N. Rosen, eds. 1975. General Relativity and Gravitation: Proceedings of the Seventh International Conference (GR7), John Wiley, New York, NY.

Shuler, K.E. and J. Weber. 1954. A microwave investigation of the ionization of hydrogenoxygen and acetylene-oxygen flames. J. Chem. Phys. 22: 491-502.

Thorne, K.S. 1994. Black Holes and Time Warps. W. W. Norton, New York, NY, p. 366.

Tobias, R.L. 2013. Email dated 7 March.

Trimble, V. 1988. 1987A: The greatest supernova since Kepler. Rev. Mod. Phys. 60: 859-871. 
Trimble, V. 2000. Obituary of Joseph Weber. Bulletin of the American Astronomical Society 32: 1691-1693.

Trimble, V. 2003. Supernovae: Ground zero and the aftermath. In R. Bandiera et al., eds. Texas in Tuscany, XXI Symposium on Relativistic Astrophysics. World Scientific, Singapore, pp. 269-284.

Trimble, V. 2014. Joseph Weber. In Hockey et al. (2014), pp. 2301-2303.

Trimble, V. 2016. Joseph Weber. In B. Wszolek and A. Kuzmica, eds. Czestochowski Kalendarz Astronomiczny 2016. Astronomica Nova, Chestochowska, Poland, pp. 171175.

Trimble, V. and J. Weber. 1973. Gravitational radiation detection experiments with Diskshaped and cylindrical antennae and the lunar surface gravimeter. In D.J. Hegyi, ed. Sixth Texas Symposium on Relativistic Astrophysics, Ann. NY Acad. Sci. 224: 93-100.

Trimble, V., W.K. Rose and J. Weber. 1973. A low-mass primary for Cygnus X-1? Monthly Notices of the Royal Astron. Soc. 162: pink pages 1-4.

Tyson, J.A. 1973. Gravitational radiation. In D.J. Hegyi, ed. Sixth Texas Symposium on Relativistic Astrophysics, Ann. NY Acad. Sci. 224: 74-92.

Weber, J. 1951. Pressure broadening of an ammonia inversion line for foreign gases. Phys. Rev. 83: 1058-1059.

Weber, J. 1953a. Amplification of microwave radiation by substance not in thermal equilibrium. Transactions of the IRE, PGED 3: 1-4.

Weber, J. 1953b. Quantum theory of a damped electrical oscillator and noise. Phys. Rev. 90: 977-982.

Weber, J. 1954a. Quantum theory of a damped electrical oscillator and noise II. The radiation resistance. Phys. Rev. 94: 211-215.

Weber, J. 1954b. Vacuum fluctuation noise. Phys. Rev. 94: 215-217.

Weber, J. 1954c. Vacuum fluctuation noise and dissipations. Phys. Rev. 96: 556-559.

Weber, J. 1955. Scattering of electromagnetic waves by wires and plates. Proc. IRE 43: 82.

Weber, J. 1956a. Exact quantum theory solution for the damped harmonic oscillator. Phys. Rev. 101: 1619-1620.

Weber, J. 1956b. Fluctuation dissipation theorem. Phys. Rev. 101: 1620-1626.

Weber, J. 1957. Maser noise considerations. Phys. Rev. 106: 537-541.

Weber, J. 1959a. Gravitational Waves. First Prize Essay, Gravity Research Foundation, New Boston, NH.

Weber, J. 1959b. Masers. Rev. Mod. Phys. 31: 681-710.

Weber, J. 1960a. Detection and generation of gravitational waves. Phys. Rev. 117: 306-313.

Weber, J. 1960b. Phase as a dynamical variable in quantum mechanics. In Proc. of Rochester Conference on Coherence of Electromagnetic Radiation.

Weber, J. 1960c. Coherence properties of electromagnetic radiation. In Proceedings of Johns Hopkins University Conf. on Electronic Countermeasure.

Weber, J. 1960d. Some aspects on noise in low noise receivers. In Proc. of MIT Symposium on Low noise Receivers.

Weber, J. 1961a. General Relativity and Gravitational Waves. Interscience Publ. NY.

Weber, J. 1961b. Quantum electronics and new gravitation experiments. In Proc. of 2nd International Conf. on Quantum Electronics.

Weber, J. 1962a. On the possibility of detection and generation of gravitational waves. In Lichnerowicz and Tonnelat (1962), pp. 441-450.

Weber, J. 1962b. Theory of methods for measurement and production of gravitational waves. In C. Møller, ed. Evidence for Gravitational Theories (Varenna 1961). Academic Press, pp. 116-140.

Weber, J. 1963a. Remarks on gravitational experiments. Nuovo Cimento 29: 930-934.

Weber, J. 1963b. Gravitation and light. In H.Y. Chiu and W.F. Hoffman, eds. Gravitation, W.A. Benjamin Inc. NY.

Weber, J. 1963c. Gravitational Waves. In H.Y. Chiu and W.F. Hoffman, eds. Gravitation, W.A. Benjamin Inc. NY.

Weber, J. 1964a. Noise considerations in gravitational experiments. Nuovo Cimento 30: $462-464$. 
Weber, J. 1964b. Gravitational radiation experiments. In C. DeWitt and B. DeWitt, eds. Relativity Groups and Topology (Les Houches 1963) Gordon \& Breach, New York, NY, pp. 865-882.

Weber, J. 1964c. Gravitation and Light. In H.Y. Chiu and W.F. Hoffmann, Gravitation and Relativity, W.A. Benjamin, pp. 90-105.

Weber, J. 1965a. Introductory Remarks: Lasers and free electron amplifiers. Annals of the NY Acad. of Sciences 122: 571-578.

Weber, J. 1965b. Some notes on masers and lasers. Proc. NY Acad. Sci. 22: 832.

Weber, J. 1966a. Gravitational shielding and absorption. Phys. Rev. 146: 935-937.

Weber, J. 1966b. Observation of the thermal fluctuations of a gravitational wave detector. Phys. Rev. Lett. 17: 1228-1230.

Weber, J. 1966c. Gravitational experiments on the lunar surface, Conference Document published as Weber 1967b.

Weber, J. 1967a. Gravitational radiation. Phys. Rev. Lett. 18: 498-501.

Weber, J. 1967b. Lunar gravity investigations. In. E. Burgess, ed., Physics of the Moon, Advances in Astronautical Sciences 13, p. 199

Weber, J. 1968a. Gravitational waves, Physics Today 21: 34-39.

Weber, J. 1968b. Gravitational radiation from the pulsars. Phys. Rev. Lett. 21: 295-296.

Weber, J. 1968c. Gravitational-wave-detector events. Phys. Rev. Lett. 20: 1307-1308.

Weber, J. 1969a, ed. Masers: A Collection of Reprints with Commentary, Vol. 9. Gordon and Breach, New York, NY.

Weber, J. 1969b, ed. Lasers: A Collection of Reprints with Commentary, Vol. 10A. Gordon and Breach, New York, NY.

Weber, J. 1969c. Evidence for the discovery of gravitational radiation. Phys. Rev. Lett. 22: $1320-1324$.

Weber, J. 1970a. Gravitational radiation experiments. Phys. Rev. Lett. 24: 276-279.

Weber, J. 1970b. Anistropy and polarization in the gravitational radiation experiments. Phys. Rev. Lett. 25: 180-184.

Weber, J. 1970c. The new gravitational radiation detectors. Lettere al Nuovo Cimento 4: 653-658.

Weber, J. 1971a. Gravitational Radiation Experiments. In C.G. Kuper and A. Peres, eds. Relativity and Gravitation, Gordon and Breach, New York, NY, pp. 309-322 (proceedings of a seminar held in Haifa honoring Nathan Rosen).

Weber, J. 1971b. The detection of gravitational waves. Scientific American 224: 22-29.

Weber, J. 1971c. Disc-cylinder Argonne-Maryland gravitational radiation experiments. Il Nuovo Cimento 4B: 197.

Weber, J. 1971d. Experimental test of symmetry of gravitational radiation. Phys. Lett. A 34: 271-273.

Weber, J. 1972a. Advances in gravitational radiation detection. General Relativity and Gravitation 3: 59 .

Weber, J. 1972b. Computer analyses of gravitational radiation detection coincidences. Nature 240: 28.

Weber, J. 1977. Gravitational radiation detector observations in 1973 and 1974. Nature 266: 243.

Weber, J. 1980. The Search for Gravitational Radiation. In A. Held, ed. General Relativity and Gravitation, Vol. 2, Plenum Publishing Co., New York, pp. 435-467.

Weber, J. 1981a. Exchange of Energy with Large Numbers of Particles. Phys. Rev. A 23: $761-762$.

Weber, J. 1981b. New method for increase of interaction of gravitational radiation with an antenna. Phys. Lett. A 81: 542-544.

Weber, J. 1984. Gravitons, neutrinos and antineutrinos. Foundations of Physics 14: 11851209.

Weber, J. 1985a. Gravitational wave experiments. In B. Korsonoglu et al. eds. High Energy Physics (in honor of P.A.M. Dirac in his Eightieth Year), Plenum Publishing Co., New York, pp. 199-210. 
Weber, J. 1985b. Method for observation of neutrinos and antineutrinos. Phys. Rev. C 31: $1468-1475$.

Weber, J. 1986a. Gravitational antennas and the search for gravitational radiation. In J. Weber and T. M. Karade, eds. Gravitational Radiation and Relativity: Proceeding of the Sir Arthur Eddington Centenary Symposium, Vol. 3, World Scientific, Singapore, pp. $1-77$.

Weber, J. 1986b. Coherent scattering of neutrinos and antineutrinos by quarks in a crystal. American Inst. Phys. Proc. 150: 1038.

Weber, J. 1988a. Apparent observation of abnormally large coherent scattering cross section using $\mathrm{KeV}$ and MeV energy antineutrinos and solar neutrinos. Phys. Rev. D 38: 32-39.

Weber, J. 1988b. Neutrinos, gravitons, metrology and gravitational radiation. In V. De Sabbata and V.N. Melnikov, eds. Gravitational Measurements, Fundamental Metrology, and Constants. NATO ASI Series C230, Kluwer, Dordrecht, pp. 467-500.

Weber, J. 1989. Gravitational antenna bandwidths and cross sections. In B.F. Schutz, ed. Gravitational Wave Data Analysis, NATO ASI C253, Kluwer, Dordrecht, pp. 195-200.

Weber, J. 1990. Gravitational radiation antennas: history, observations, and lunar surface operations. In A.E. Potter and T.L. Wilson, eds. Physics and Astrophysics from a Lunar Base, AIP Conf. Proc. 202: 159-202.

Weber, J. 1991a. Velocity of propagation of gravitational radiation, mass of the graviton, range of the gravitational force, and the cosmological constant. In A. Zichichi et al., eds. Gravitation and Modern Cosmology: the Cosmological Constant Problem (in honor of 75th birthday of Peter Bergmann) Plenum Publishing Co., New York, pp. 17-20.

Weber, J. 1991b. New methods for neutrino detection, and solar neutrino interactions with a single-crystal earth core. In S. Flodmark, ed. Proc. of Conf. on New Approaches in Geomagnetism and the Earth's Rotation. World Scientific, Singapore, pp. 199-220.

Weber, J. 1992a. Supernova 1987A; gravitational-wave antenna observations, cross-sections, correlations with six elementary particle detectors, and resolution of past controversies. In A.I. Janis and J.R. Porter, eds. Recent Advances in General Relativity, Birkhauser, Boston, pp. 230-240.

Weber, J. 1992b. Gravitational radiation antenna observations, theory of sensitivity of bar and interferometer systems and resolution of past controversies. In N. Sanchez and A. Zichichi, eds. Current Topics in Astrofundamental Physics, World Scientific, Singapore, pp. 508-534.

Weber, J. 1992c. Neutrinos and antineutrinos in astronomy and astrophysics. In N. Sanchez and A. Zichichi as above, pp. 560-578.

Weber, J. 1993. Gravitational experiments at supercolliders. In W. Schroeder, ed. The Earth and the Universe. Festschrift in honour of Hans-Juergen Trader. Science Editions, Bremen, pp. 439-451.

Weber, J. 1994. Supercollider gravitational experiments. In V. de Sabbata and Ho Tso-Hsuiu, eds. Cosmology and Particle Physics, NATO ASI C427, Kluwer, Dordrecht, pp. 271-278.

Weber, J. 1998. Gravitational radiation antenna backgrounds and cross sections. Physics Essays 11: 593-599.

Weber, J. 1999. Correlated gamma ray trigger times with gravitational radiation detector pulses from the bursting pulsar J1744-28. Physics Essays 12: 781-784.

Weber, J. 2000. Gravitational radiation-antenna observations. Submitted, accepted, proofread. If published, in a journal not covered by ADS.

Weber, J. and G. Hinds. 1962. Interaction of Photons and Gravitons. Phys. Rev. 128: 24142421.

Weber, J. and K.J. Laidler. 1950. Variations of rate of desorption with extent of surface coverage. J. Chem. Phys. 18: 1416-1418.

Weber, J. and K.J. Laidler. 1951a. Kinetics of the ammonia-deuterium exchange by a microwave method. J. Chem. Phys. 19: 381-382.

Weber, J. and K.J. Laidler. 1951b. Microwave spectroscopic investigations of the kinetics of the heterogeneous ammonia deuterium exchange. J. Chem. Phys. 19: 1089-1096.

Weber, J. and J. Larson. 1966. Operation of LaCoste Romberg Gravimeter at sensitivity approaching the thermal fluctuation limits. J. Geophys. Res. 71: 6005-6009. 
Weber, J. and K.E. Shuler. 1954. A microwave investigation of the ionization of hydrogenoxygen and acetylene-oxygen flames. J. Chem. Phys. 22: 491.

Weber, J. and J.A. Wheeler. 1957. Reality of the cylindrical gravitational waves of Einstein and Rosen. Rev. Mod. Phys. 29: 509-515.

Weber, J. and V. Trimble. 1973. On the response of a gravitational radiation detector to magnetic field fluctuations. Phys. Lett. 45A: 353-354.

Weber, J., V.H. Hughes, P. Kafka, R.W.P. Drever, C.W. Misner and J.A. Tyson. 1973. General discussion on gravitational waves. Ann. NY Acad. Sci. 224: 100-107.

Weber, J., M. Lee, D.J. Gretz, G. Rydbeck, V.L. Trimble and S. Steppel. 1977. New gravitational radiation experiments. Phys. Rev. Lett. 31: 779-783.

Weber, J., V. Ferrari, G. Pizzella and M. Lee. 1982. Search for correlations between the University of Maryland and the University of Rome gravitational radiation antennas. Phys. Rev. D 25: 2471.

Weber, J. and B. Radak. 1996. Search for correlations of gamma ray bursts with gravitational radiation antenna pulses. Nuovo Cimento B 111: 687-692.

Weiss, R. 1972. Lincoln Research Laboratory of Electronics (MIT) Quarterly Report No. $105,54076$.

Weyl, H. 1922. Space-Time Matter. Methuen, London.

Weyl, H. 1944. How far can one get with a linear field theory of gravitation in flat space-time? Am. J. Math. 66: 591-604.

Wheeler, J.A. and R.P. Feynman. 1948. Interaction with the absorber as the mechanism of radiation. Rev. Mod. Phys. 17: 157-181.

Zeldovich, Ya.B. and O.H. Guseinov. 1966. Collapsed stars in binaries. Astrophysical Journal 144: $840-842$.

Open Access This is an open access article distributed under the terms of the Creative Commons Attribution License (http://creativecommons.org/licenses/by/4.0), which permits unrestricted use, distribution, and reproduction in any medium, provided the original work is properly cited. 